\title{
Lista de Cyanobacteria do Estado de São Paulo
}

\author{
Célia Leite Sant'Anna ${ }^{1,4}$, Luis Henrique Zanini Branco ${ }^{2}$, \\ Watson Arantes Gama Júnior ${ }^{1}$ \& Vera Regina Werner ${ }^{3}$ \\ ${ }^{1}$ Instituto de Botânica, Núcleo de Pesquisa em Ficologia, Av. Miguel Estéfano 3687, CEP 04301-012, \\ São Paulo,SP, Brasil,e-mail: celialsant@yahoo.com.br;watsonarantes@gmail.com \\ ${ }^{2}$ Departamento de Zoologia e Botânica, Universidade Estadual Paulista - UNESP, Rua Cristóvão Colombo, \\ 2265, CEP 15054-000, São José do Rio Preto, SP, Brasil. e-mail: branco@ibilce.unesp.br \\ ${ }^{3}$ Museu de Ciências Naturais, Fundação Zoobotânica do Rio Grande do Sul, CP 1188, CEP 90001-970, \\ Porto Alegre, RS, Brasil, e-mail:vera-werner@fzb.rs.gov.br \\ ${ }^{4}$ Autor para correspondência: Célia Leite Sant’Anna, e-mail: celialsant@yahoo.com.br
}

SANT'ANNA, C.L., BRANCO, L.H.Z., GAMA JÚNIOR, W.A. \& WERNER, V.R. Checklist of Cyanobacteria from São Paulo State, Brazil. Biota Neotrop. 11(1a): http://www.biotaneotropica.org.br/v11n1a/en/abstract?i nventory+bn0171101a2011

\begin{abstract}
Based on the literature about the cyanobacteria from Brazil and particularly from São Paulo State, the list of Brazilian flora and the data bank of herbaria collections, a total of 460 species were referred to Brazil and 378 to São Paulo State. Taking into account that the group of cyanobacteria presents around 2800 species, these numbers represent much less than $20 \%$ of the known species. Considering the diversity of environments and habitats in the tropical/subtropical biomes compared to the reduced number of known species, this biodiversity is certainly underestimated and should be much larger.
\end{abstract}

Keywords: Cyanobacteria; biodiversity of the State of São Paulo; BIOTA/FAPESP Program.

Number of species: In the world: 2.800; In Brazil: 460; Estimated in São Paulo State: 450.

SANT'ANNA, C.L., BRANCO, L.H.Z., GAMA JÚNIOR, W.A. \& WERNER, V.R. Lista de Cyanobacteria do Estado de São Paulo. Biota Neotrop. 11(1a): http://www.biotaneotropica.org.br/v11n1a/pt/abstract?invent ory+bn0171101a2011

Resumo: Com base no levantamento bibliográfico realizado sobre as cianobactérias citadas para o Brasil e para o Estado de São Paulo em particular, além de consulta à lista de espécies da flora brasileira e aos bancos de dados de coleções paulistas, encontramos um total de 460 espécies citadas para o Brasil e 378 para o estado de São Paulo. Considerando que o grupo tem ao redor de 2800 espécies, estes números representam bem menos de $20 \%$ das espécies conhecidas. Assim, frente a diversidade de ambientes e habitats existentes nos biomas tropicais/subtropicais, o reduzido número de espécies já conhecidas indica que certamente essa biodiversidade está subestimada e deve ser muito maior do que identificamos até agora.

Palavras-chave: Cyanobacteria, biota paulista, Programa BIOTA/FAPESP.

Número de espécies: No mundo: 2.800; No Brasil: 460; Estimadas no estado de São Paulo: 450. 


\section{Introdução}

As cianobactérias constituem um grupo particular de procariotos, pois apresentam características de algas e de bactérias. Possuem em comum com as algas a fotossíntese oxigênica, a presença de clorofila a que é o pigmento comum a todos eucariotos fotossintetizantes, além de outros como as ficobilinas (presas aos tilacóides) e pigmentos assessórios como os carotenóides. Portanto, são produtores primários como as algas. No entanto, assim como as demais bactérias não possuem núcleo e plastos, a parede celular é de peptidoglicano e não apresentam reprodução sexuada (Lee 2008).

A maioria das cianobactérias ocorre em água doce, mas são também componentes naturais dos ecossistemas marinhos, águas salobras, solos, além de crescerem nos mais variados tipos de substratos como rochas, pedras, barrancos, areia, troncos de árvore e substratos artificiais. Podem ser microscópicas ou formar talos macroscópicos principalmente em ambientes terrestres. São dos poucos organismos que estão aptos a se desenvolverem em ambientes extremos tais como, neve, fontes termais, desertos, lagos hipersalinos e lagos alcalinos (Seckbach 2007). Podem ainda ocorrer em simbiose com algas, plantas, fungos (liquens) e animais. As cianobactérias podem ser microscópicas ou formar talos macroscópicos geralmente em ambientes terrestres.

Embora as cianobactérias sejam conhecidas como cosmopolitas este conceito precisa ser tomado com muita cautela, pois algumas espécies são amplamente distribuídas, mas a maior parte do grupo ocorre em ambientes restritos e bem delimitados (Komárek 1985, 1994; Komárek \& Komárková-Legnerová 2007). Além disso, muitas espécies são restritas a zonas temperadas e outras são tipicamente tropicais, o que também vai contra o conceito de cosmopolitismo desse grupo de organismos. É possível considerar, portanto, que algumas espécies apresentam ampla distribuição em diferentes regiões do mundo, mas sempre ocorrem em um dado tipo de ambiente, refletindo suas preferências ecológicas e adaptações a determinados habitats.

As cianobactérias têm papel fundamental em ambientes aquáticos continentais, pois, além de serem importantes produtores primários, podem formar florações e produzir toxinas, causando diversos desequilíbrios ambientais e constituindo também problema de saúde pública. Como vários grupos de cianobactérias são capazes de fixar nitrogênio atmosférico, estes organismos ainda têm papel fundamental no ciclo biogeoquímico do nitrogênio, tanto nos mares como nos ambientes terrestres (Howarth et al. 1988, Fiore et al. 2005)

Em relação à biodiversidade das cianobactérias, a literatura mundial tem revelado que os trópicos/subtrópicos são ainda muito pouco estudados e a sua biodiversidade está seguramente subestimada. Acredita-se que menos de $10 \%$ da diversidade de cianobactérias tropicais é conhecida (Komárek 2006). Os ambientes aquáticos continentais têm sido mais frequentemente estudados nas regiões tropicais e o conhecimento da flora de cianobactérias, principalmente no estado de São Paulo, é um pouco mais efetivo. Quando se consideram, entretanto, os ambientes marinhos e terrestres das regiões tropicais do mundo, conclui-se que essa flora é extremamente mal conhecida e o Brasil não é exceção. Levando-se em conta a riqueza de ambientes e habitats existentes nos múltiplos biomas das regiões tropicais/subtropicais frente ao reduzido número de espécies conhecidas, certamente essa biodiversidade deve ser muito maior do que conhecemos até agora. Este fato é comprovado pela literatura específica que freqüentemente apresenta descrições de novas espécies ou mesmo gêneros para ambientes tropicais (Branco et al. 2009, Sant'Anna et al. 2007, 2010, 2011a,b). No Brasil, até aproximadamente à década de 1980 , mais de $90 \%$ do que se conhecia sobre cianobactérias era referente a ambientes aquáticos continentais (lênticos, em especial). Foi a partir da década de 90 que os ambientes marinhos e terrestres passaram a ser mais intensamente estudados e com isso houve um acréscimo significativo no conhecimento da biodiversidade de cianobactérias brasileiras.

Com base no presente cenário, é muito importante discutir formas de estudar e conhecer a grande riqueza de cianobactérias no Brasil, bem como seu potencial biotecnológico, frente à rápida destruição dos seus ambientes com consequente perda da biodiversidade.

\section{Metodologia}

A presente lista de espécies de cianobactérias foi elaborada com base, principalmente, no acervo do Herbário Científico do Estado "Maria Eneida P. Kauffman Fidalgo" (SP) do Instituto de Botânica. Além dessa coleção, foram consultados o Herbário da UNESPSão Jose do Rio Preto (SJRP), a Lista do Brasil (Werner 2010) e a literatura científica específica sobre flora/taxonomia de cianobactérias do Estado de São Paulo.

Os dois Herbários mencionados são os únicos no Estado a apresentar coleções organizadas de espécimes de cianobactérias, tanto de água doce, como de ambientes marinhos e terrestres. Foi importante consultar a literatura específica, pois diversos trabalhos descrevem e ilustram as espécies, mas não mencionam o herbário onde o material está depositado.

Com o intuito de não subestimar a biodiversidade das cianobactérias no Estado de São Paulo, essas informações também foram adicionadas à lista de espécies. O sistema de classificação adotado foi o de Hoffmann et al. (2005) com modificações de Komárek (2006). Para os gêneros Aphanocapsa, Aphanothece, Synechocystis e Merismopedia seguimos o proposto na base de dados Cyano. DB (Komárek \& Hauer 2011).

\section{Resultados e Discussão}

Lista das espécies de cianobactérias do estado de São Paulo (Tabela 1).

\section{Comentários}

No estado de São Paulo há destacado conhecimento da diversidade de cianobactérias frente ao dos outros estados, mesmo considerando que os dados possam estar incompletos (Werner 2010). Tal descompasso entre o conhecimento da biodiversidade de cianobactérias do estado de São Paulo em comparação com os demais estados do país pode ser claramente detectado quando se agrupam os dados por regiões geográficas: para a região Norte são citados 21 gêneros e 33 espécies, para o Centro-Oeste 27 gêneros e 46 espécies, para o Sul 36 gêneros e 78 espécies e para o Sudeste são citados 145 gêneros e 264 espécies. Apenas para se ter idéia dos valores do estado de São Paulo em relação aos demais, a Lista do Brasil menciona 81 gêneros e 166 espécies de cianobactérias para este Estado. Certamente esta discrepância nos valores de riqueza de espécies nas diferentes regiões do país deve-se à localização da maior parte dos especialistas em instituições paulistas, o que possibilitou grande avanço nos estudos sobre as cianobactérias brasileiras, sobretudo do estado de São Paulo.

Com base na lista de espécies presentemente elaborada, o conhecimento da diversidade de cianobactérias no estado de São Paulo, embora em situação muito melhor que a dos demais estados do Brasil, continua ainda aquém do esperado. Considerando que o grupo apresenta ao redor de 2800 espécies (Komárek \& Anagnostidis 1998), seria de se esperar que pelo menos $40 \%$ dessas fossem mencionadas para o Brasil, um país de vasto território e diversidade invejável de ambientes aquáticos e terrestres. No entanto, verificamos que 460 espécies foram citadas para o Brasil e 378 para o estado de 
Lista de Cyanobacteria do Estado de São Paulo

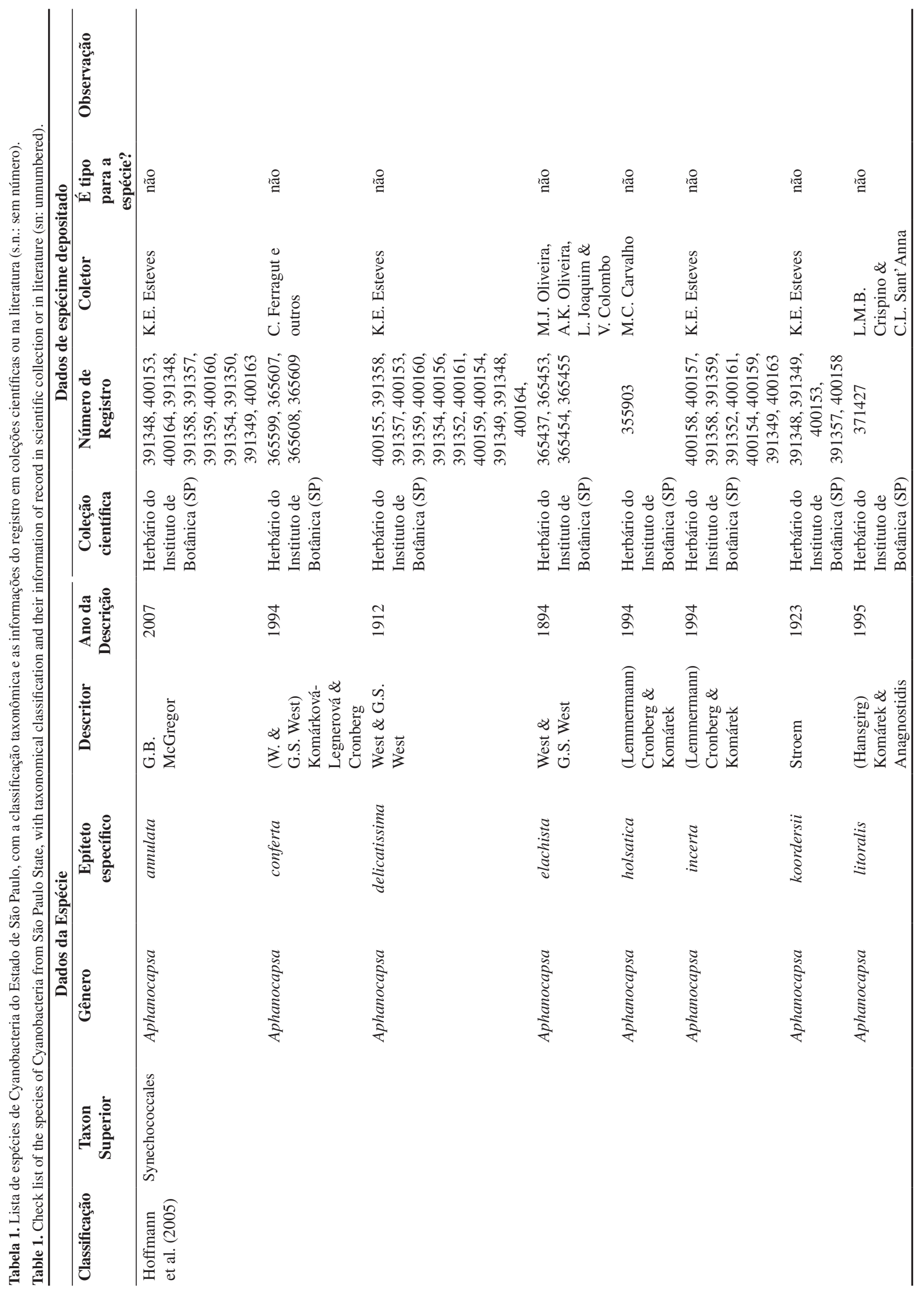




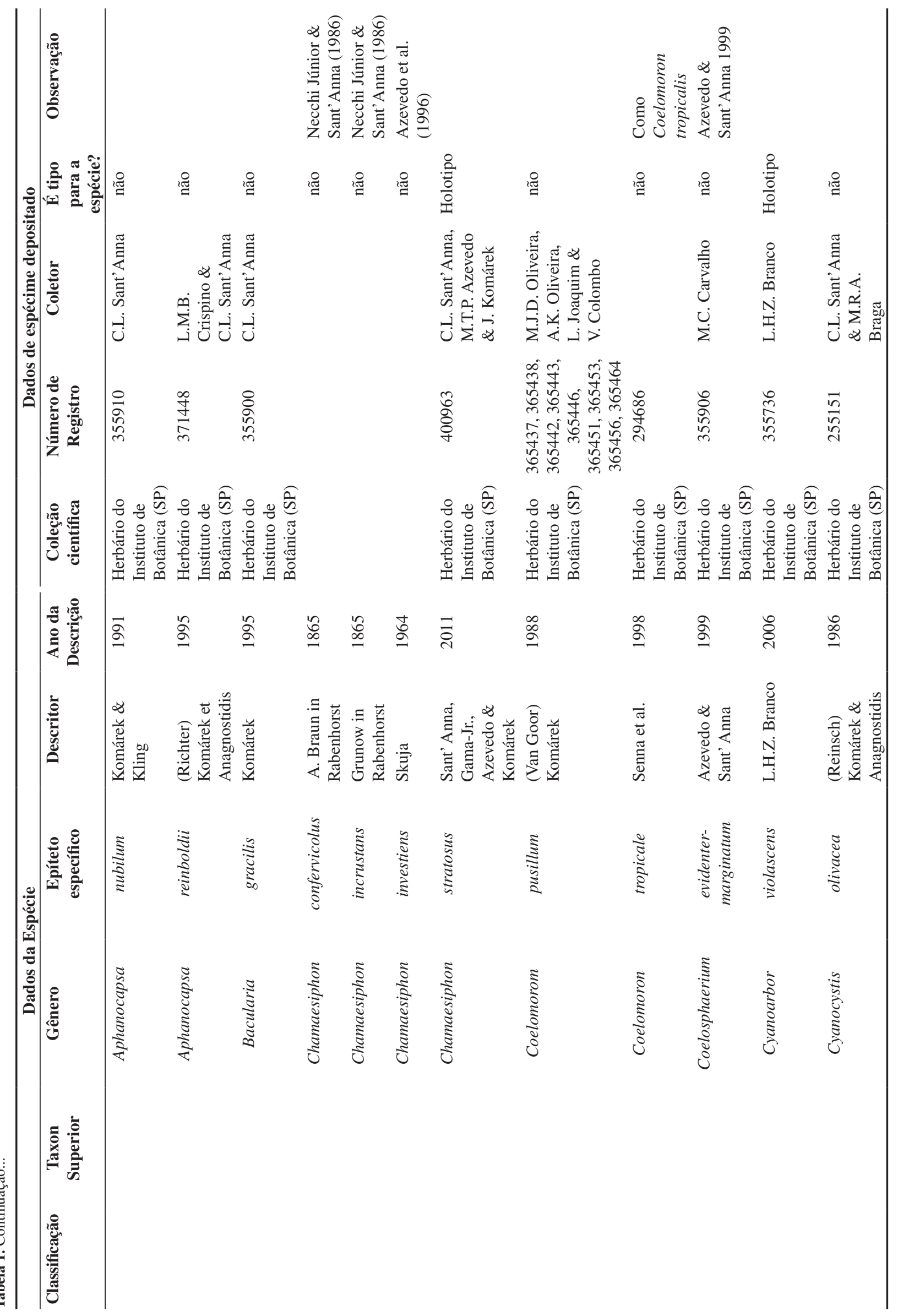




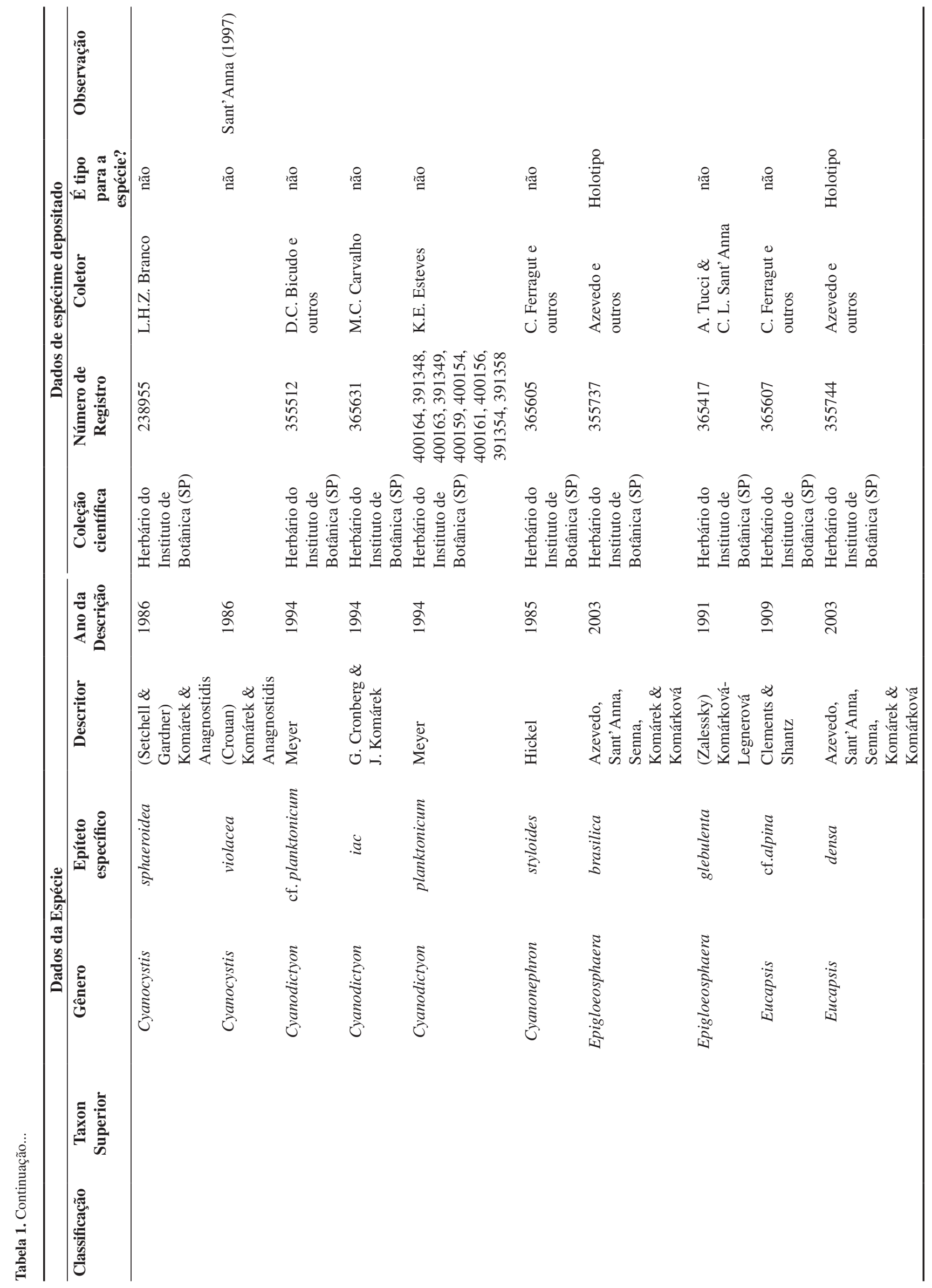




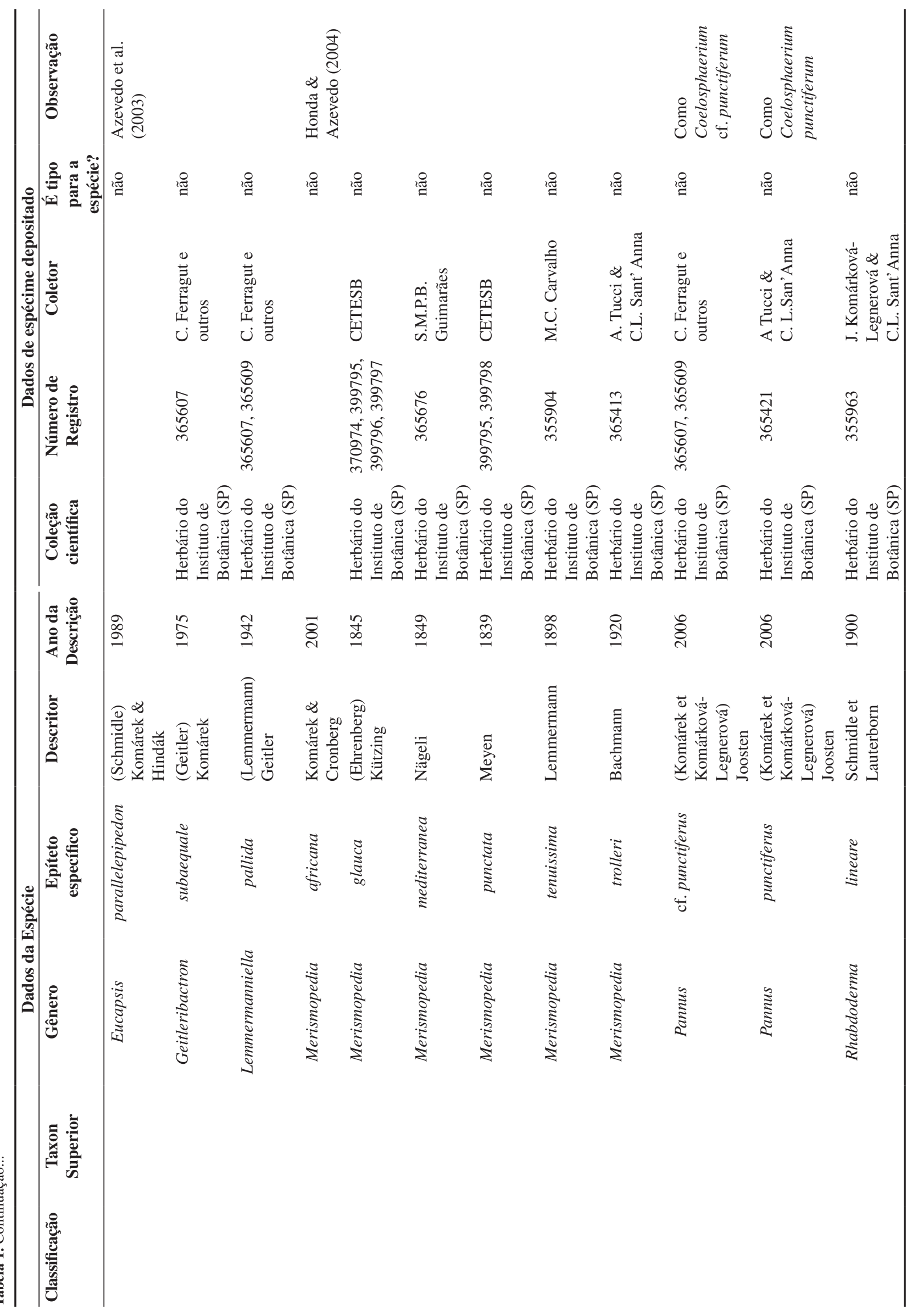




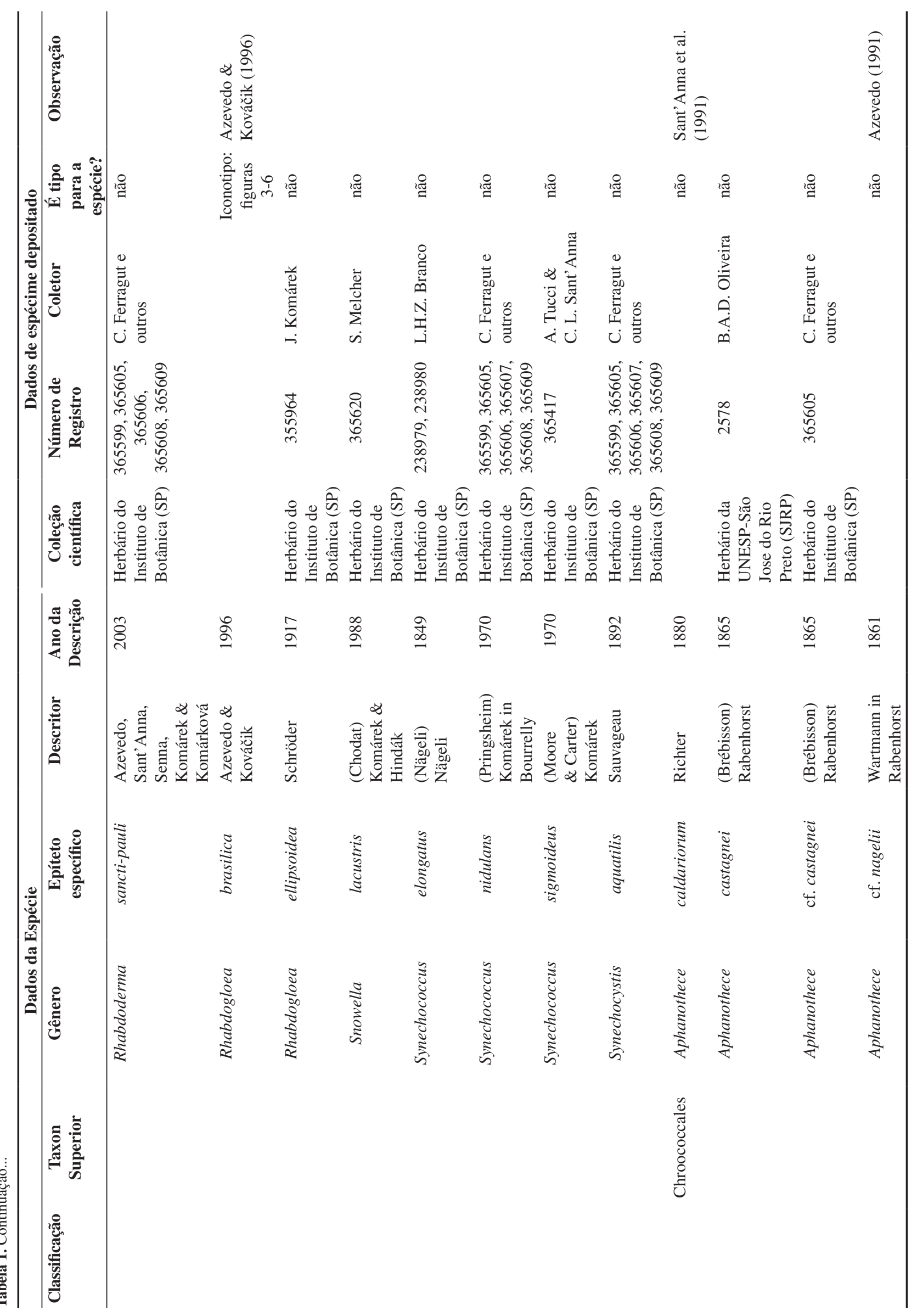




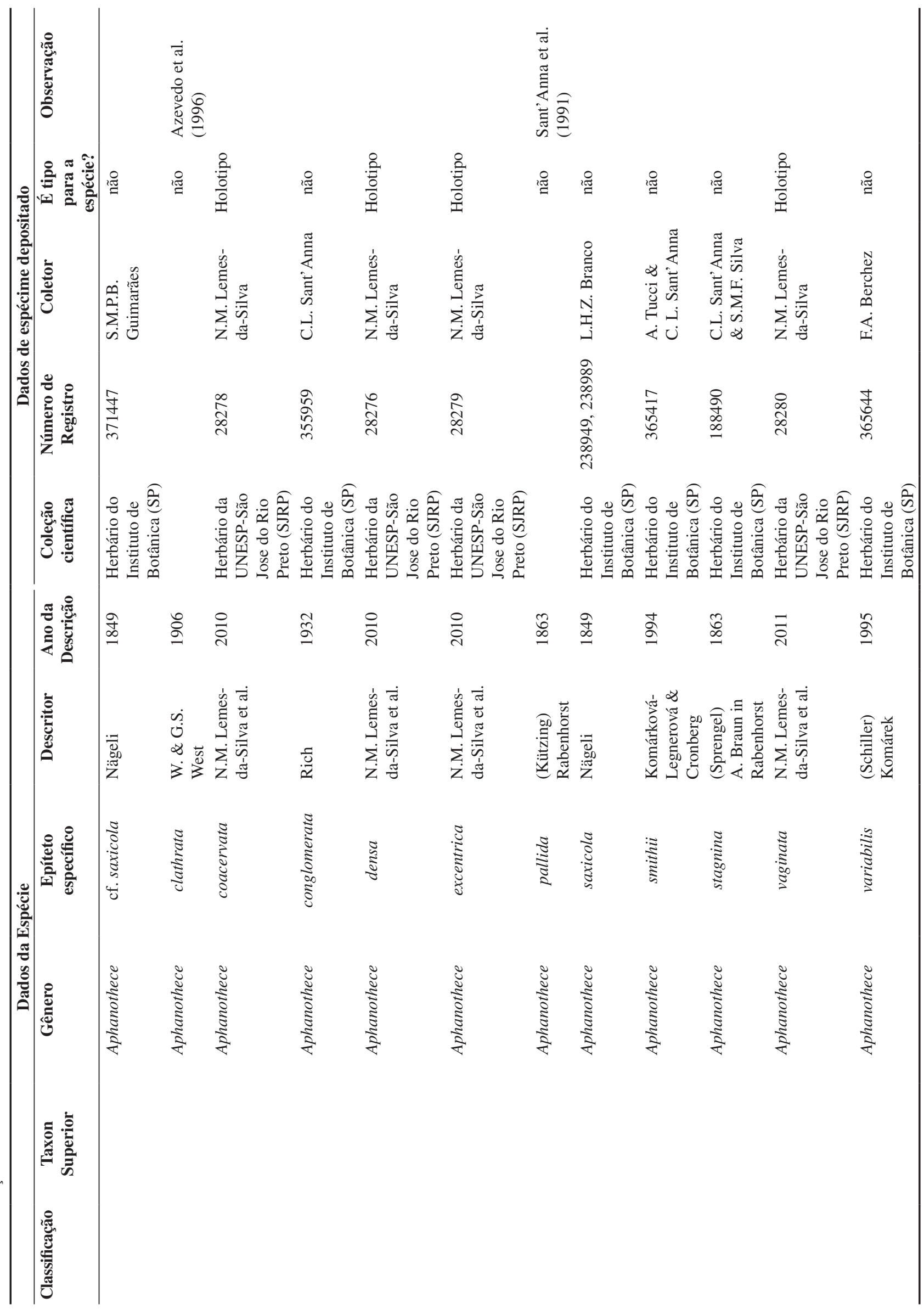




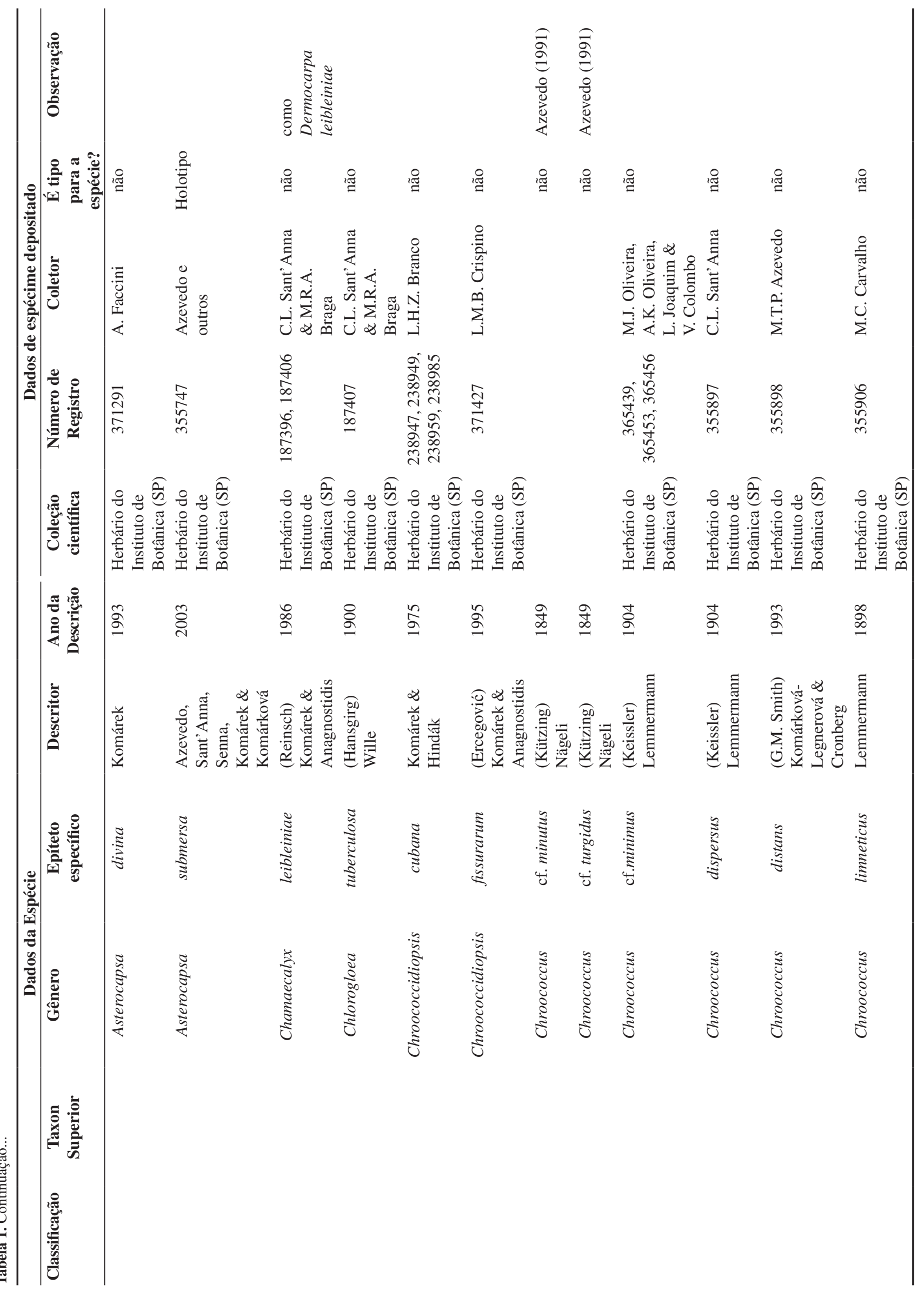


Sant'anna, C.L. et al.

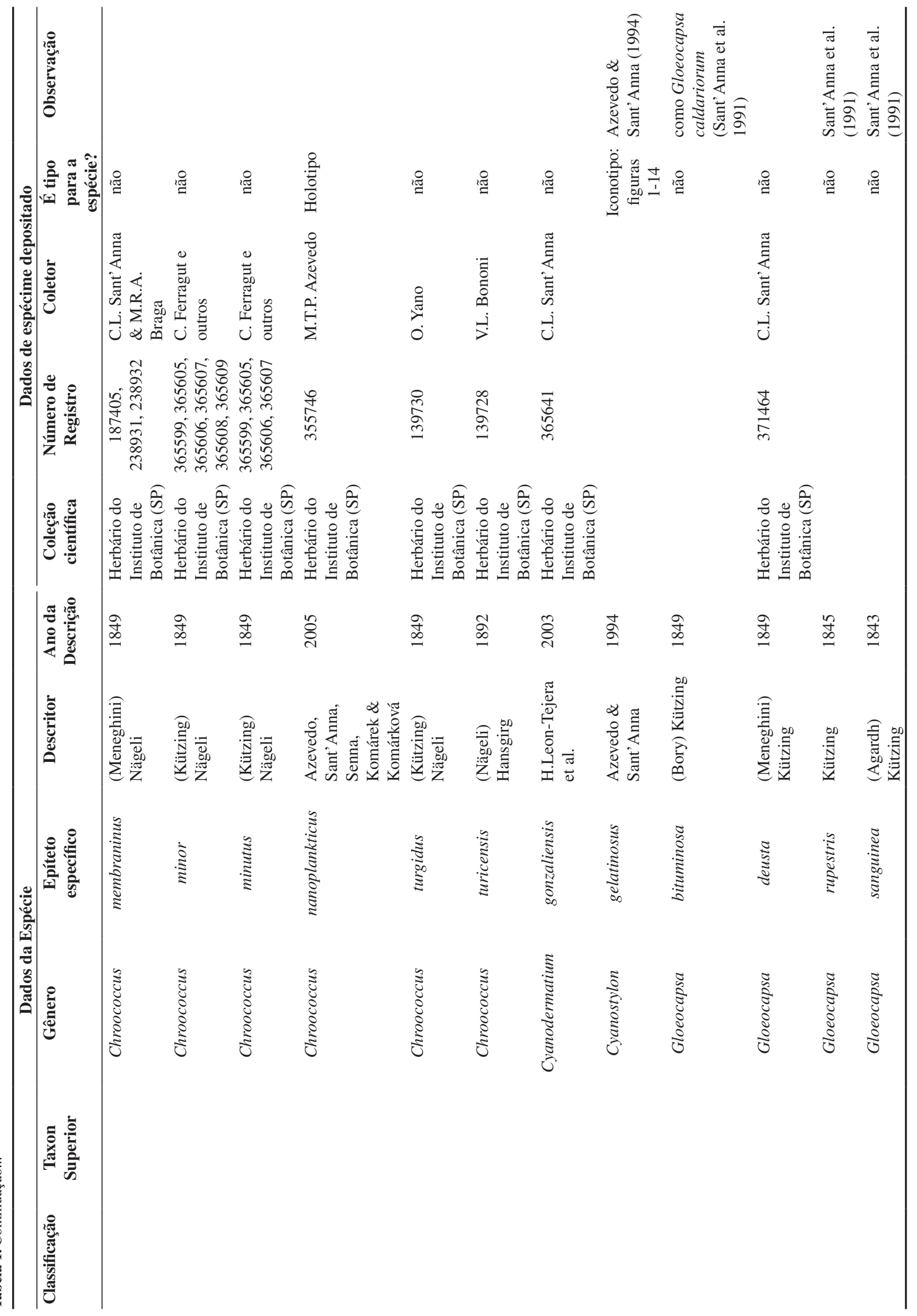




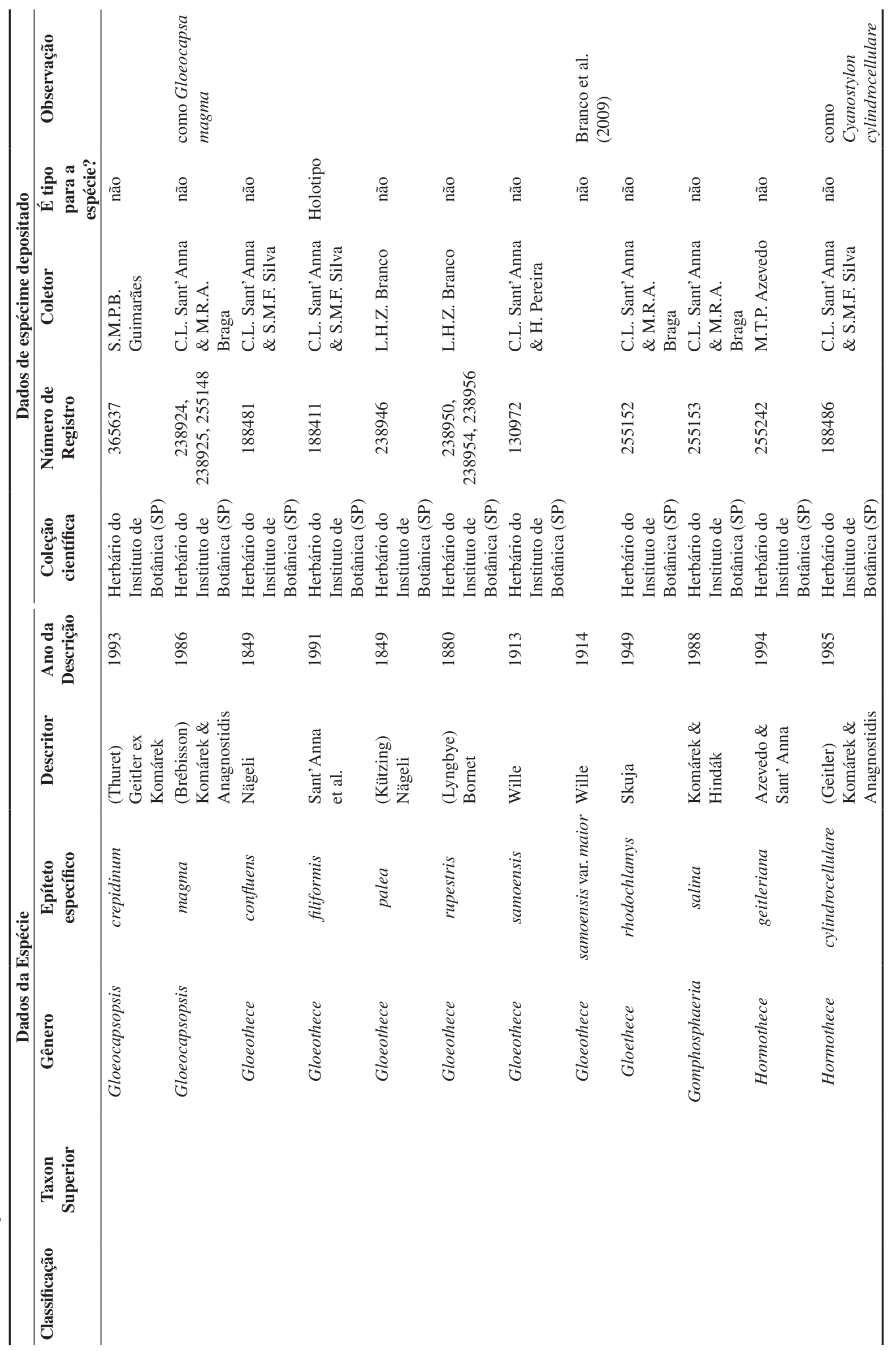


Sant'anna, C.L. et al.

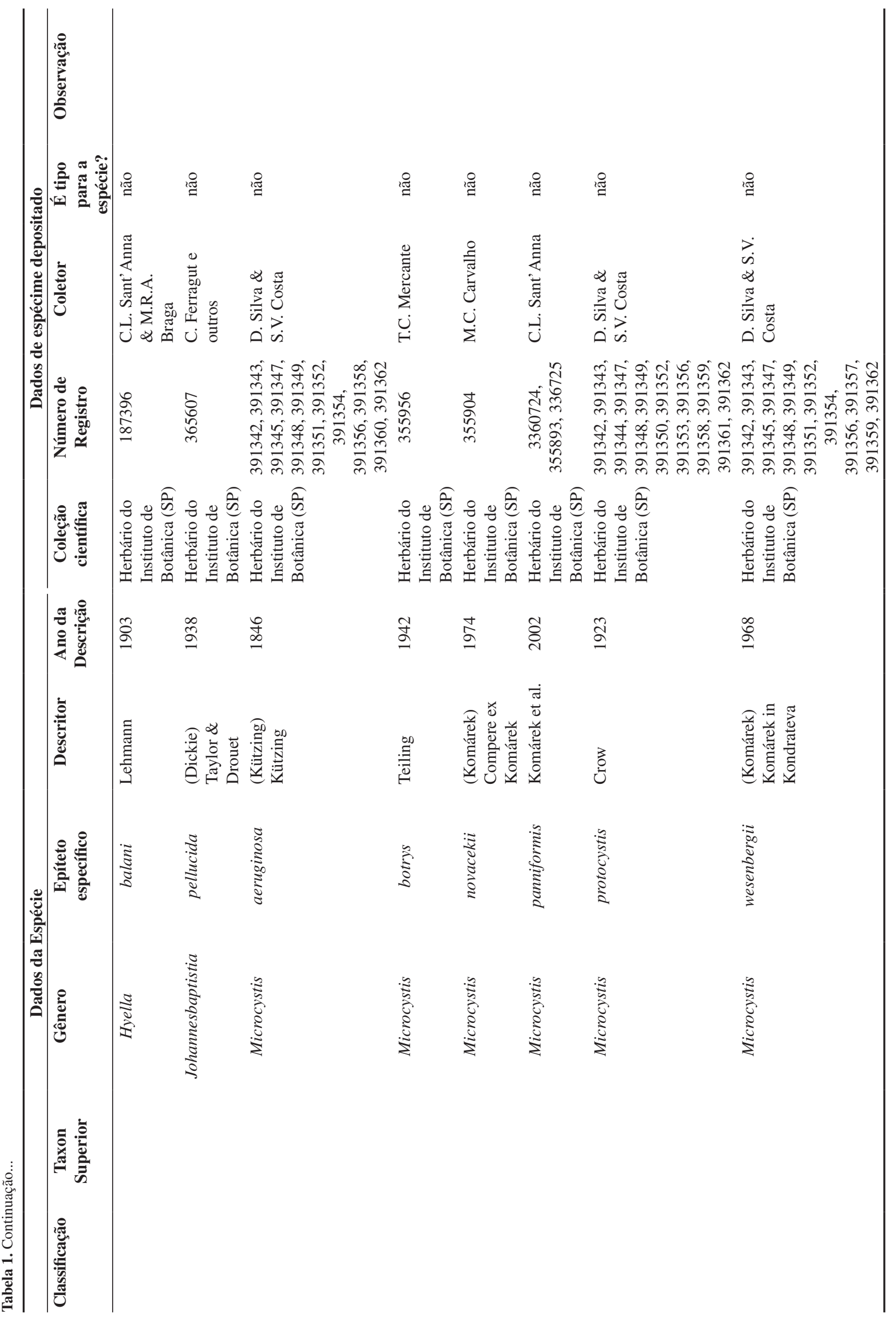




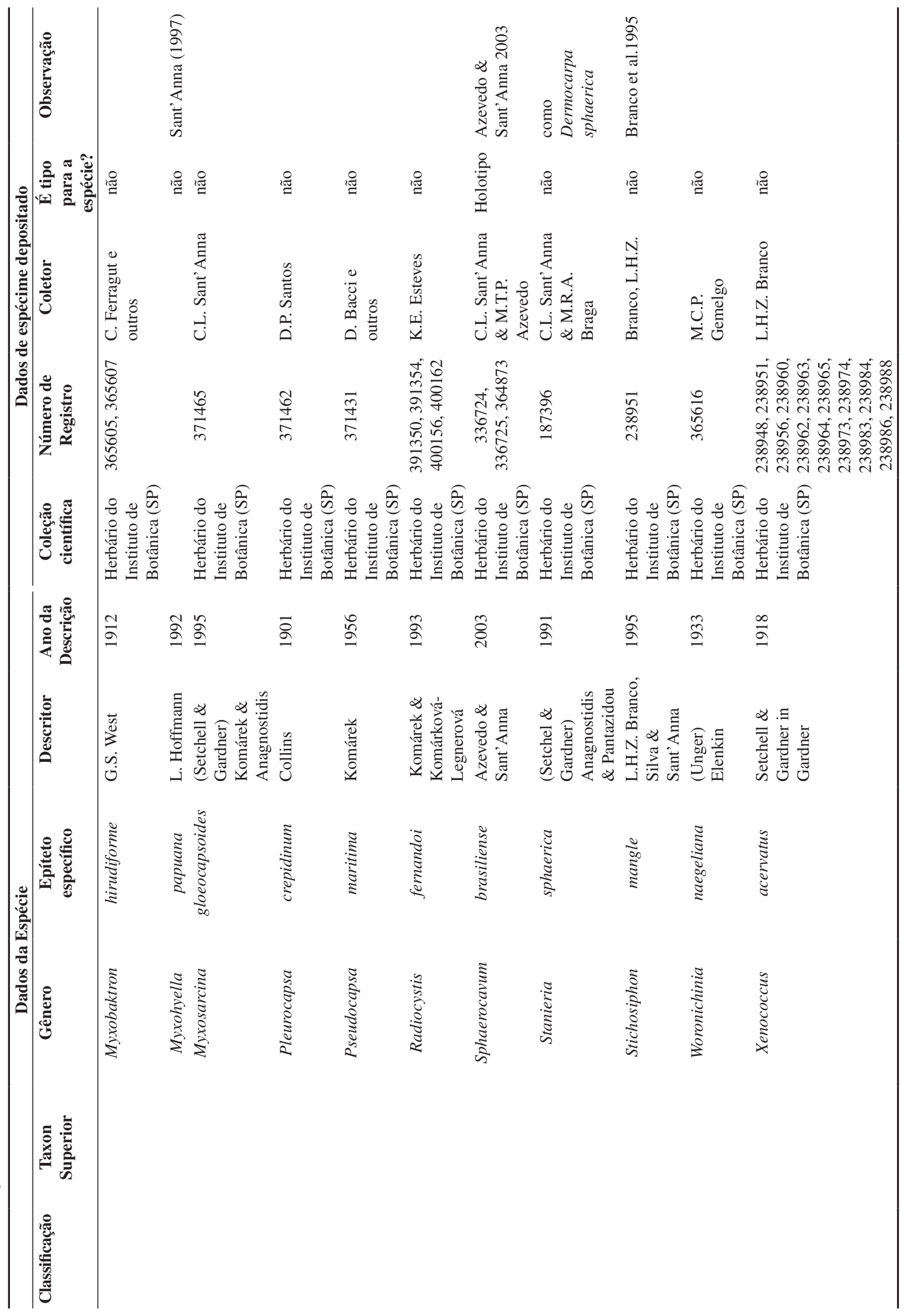




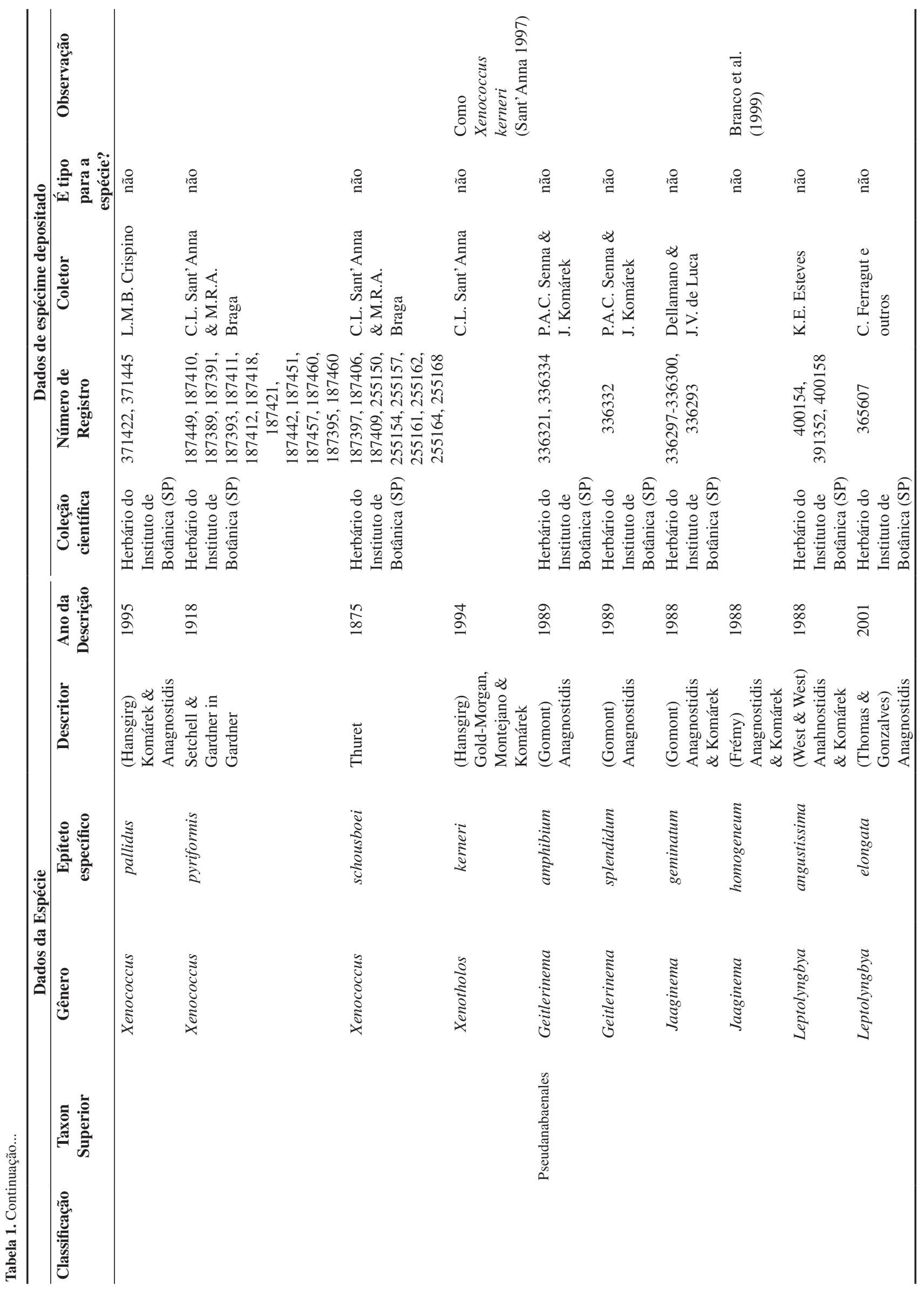




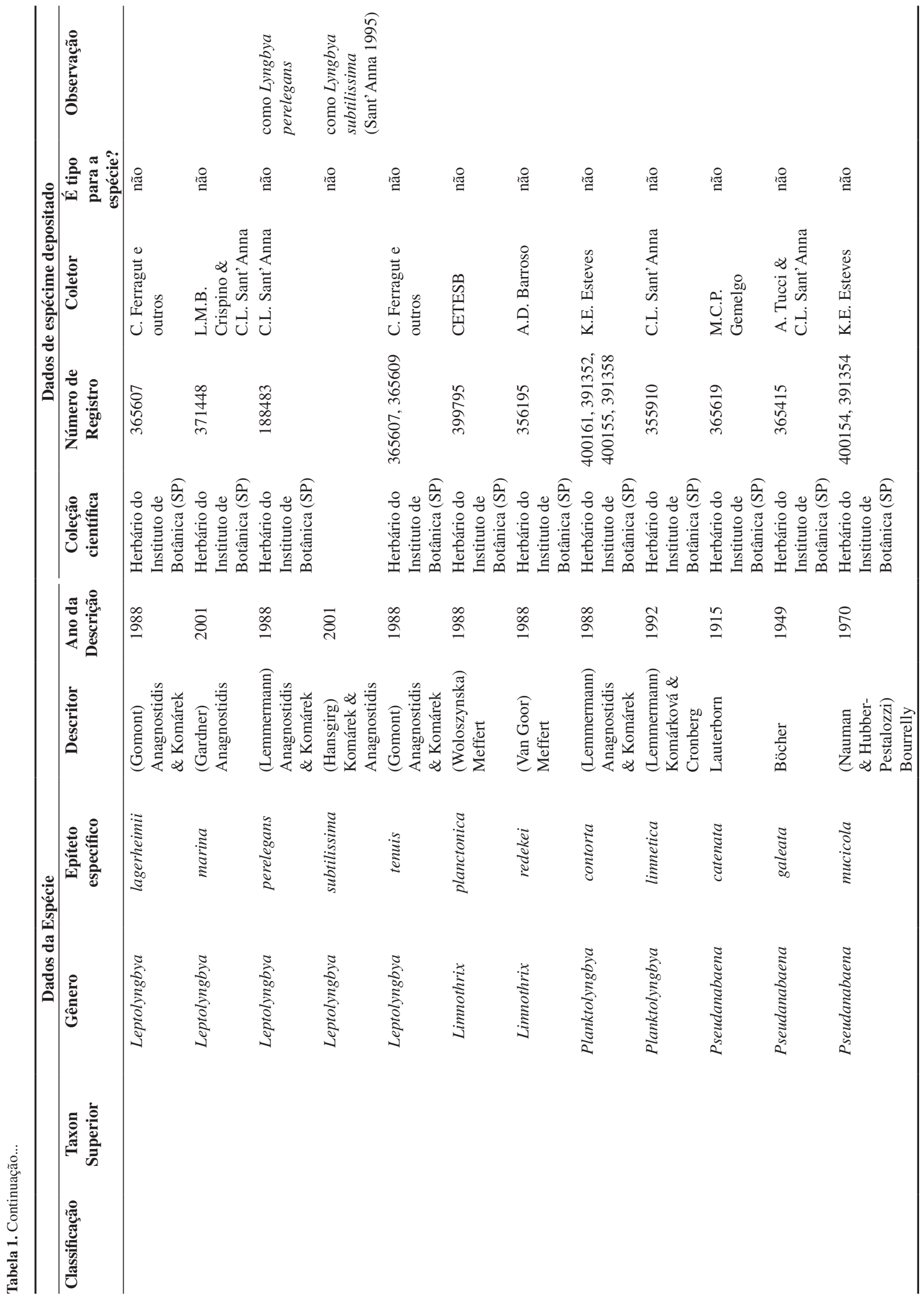




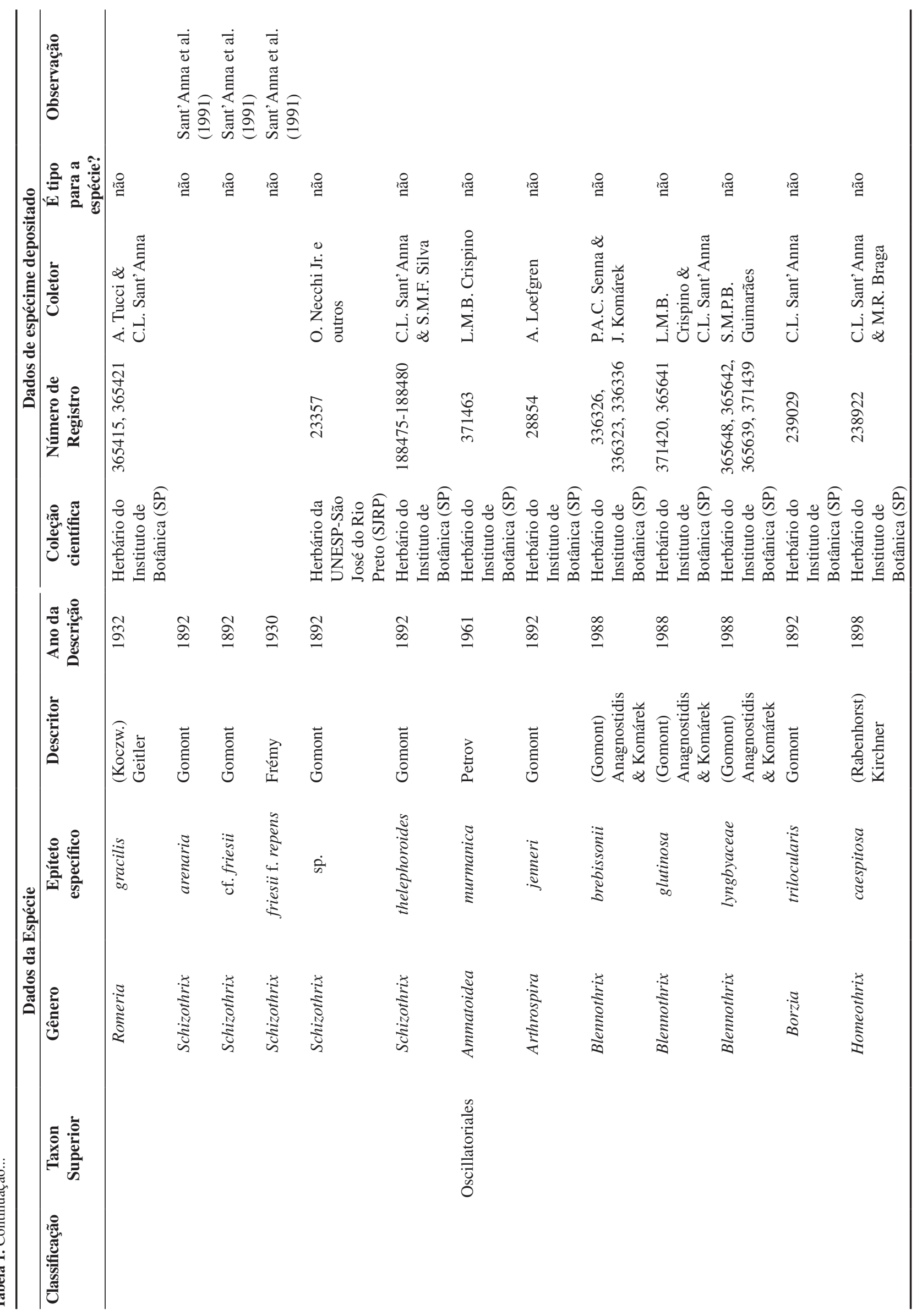




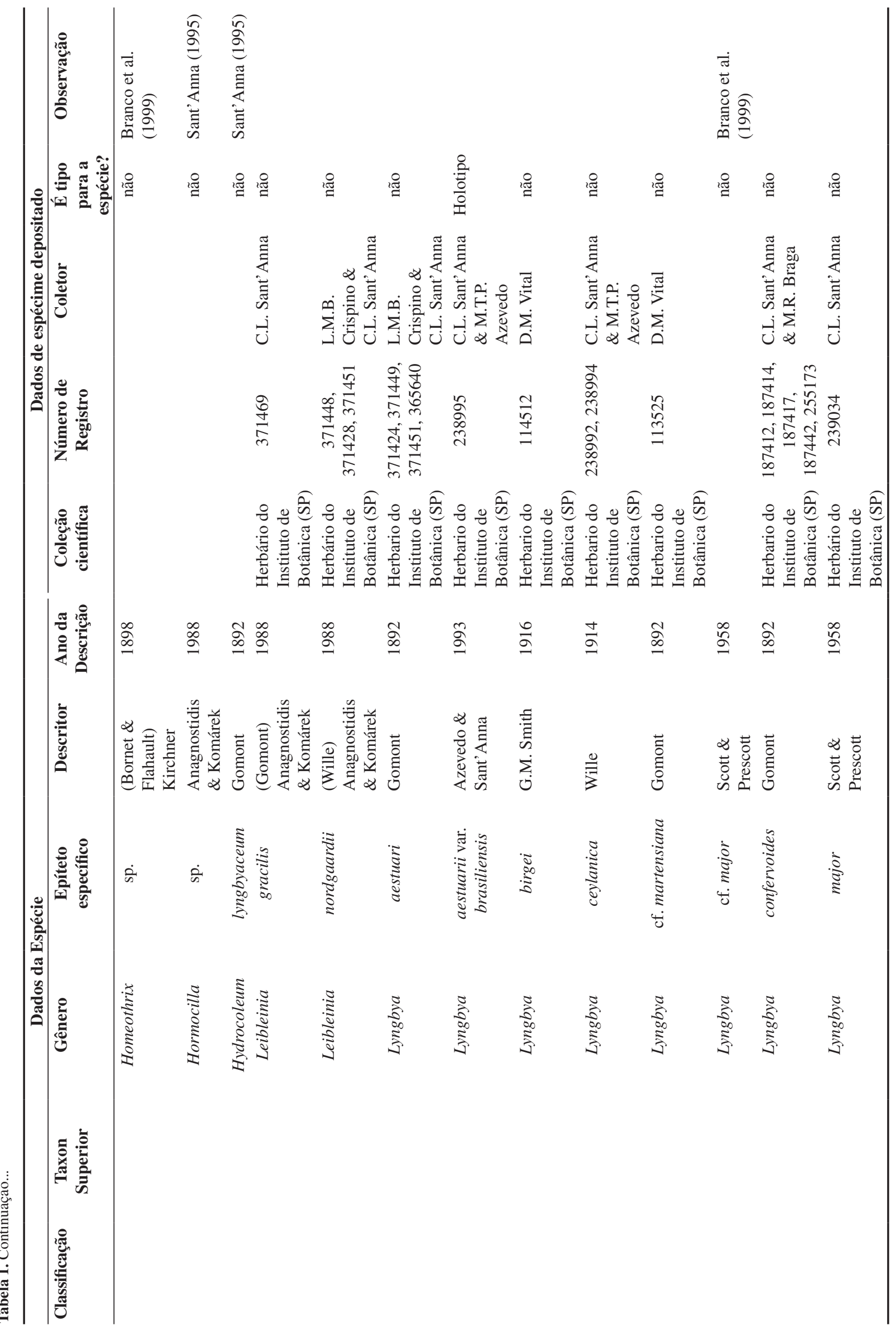


Sant'anna, C.L. et al.

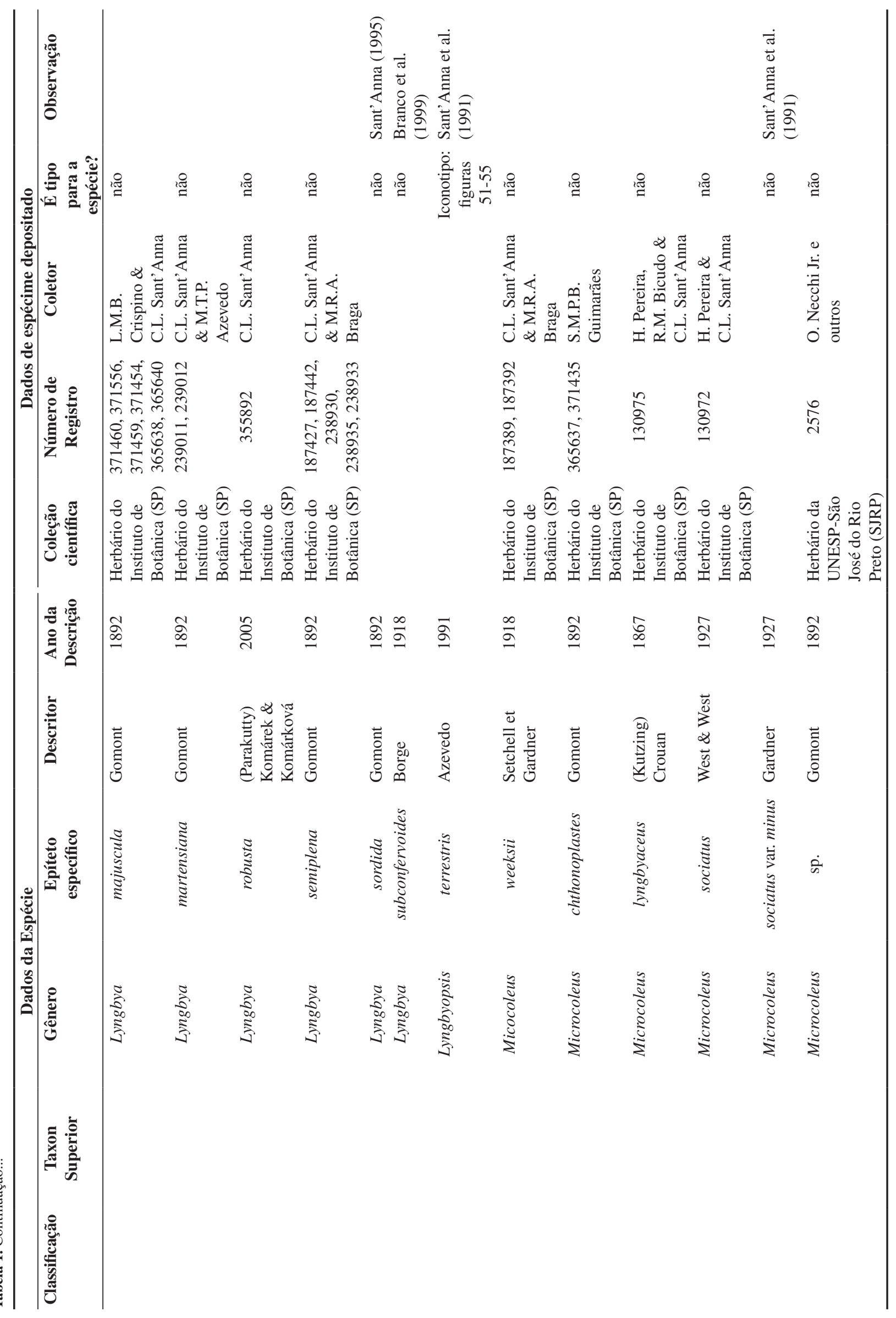




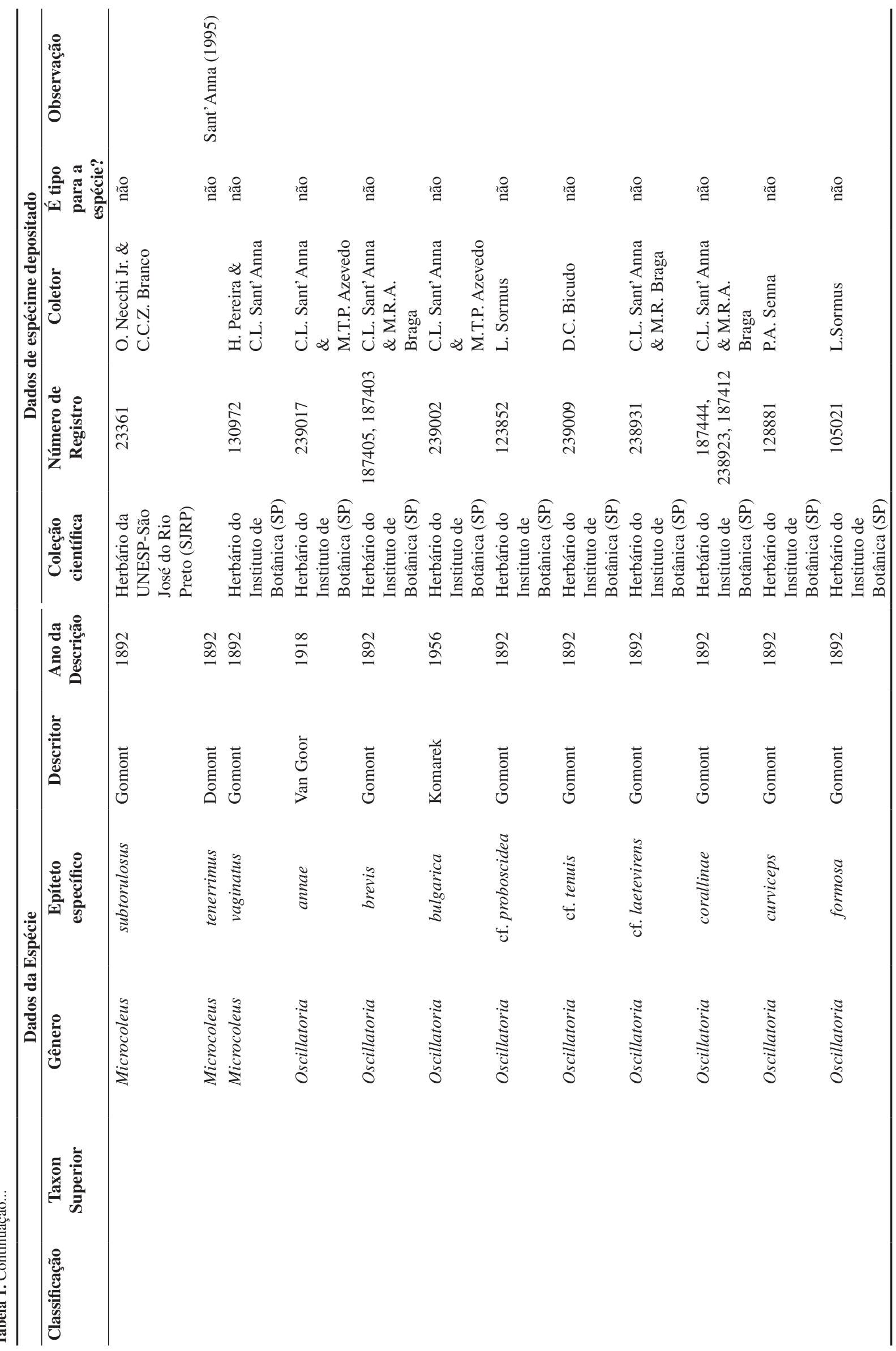


Sant'anna, C.L. et al.

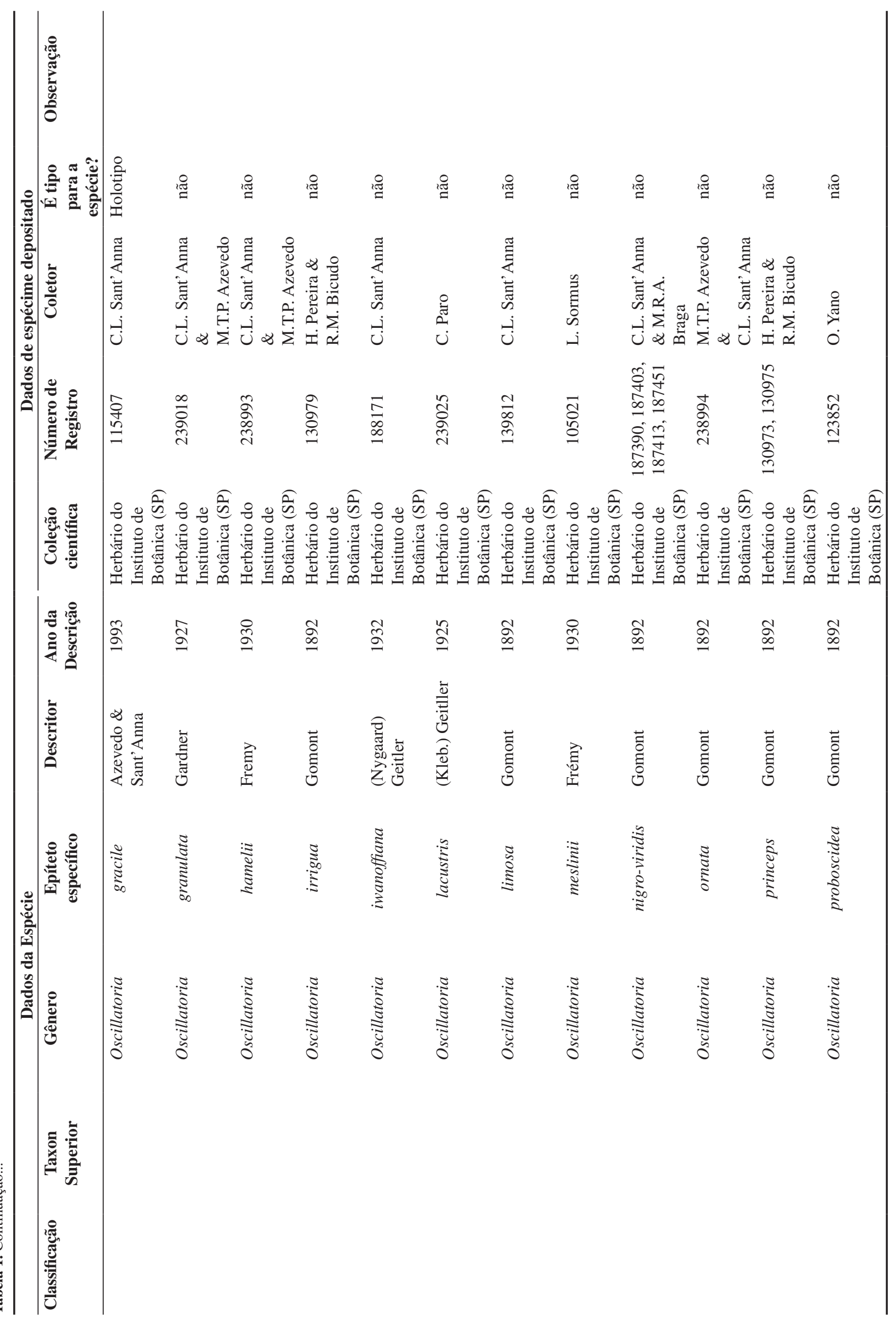




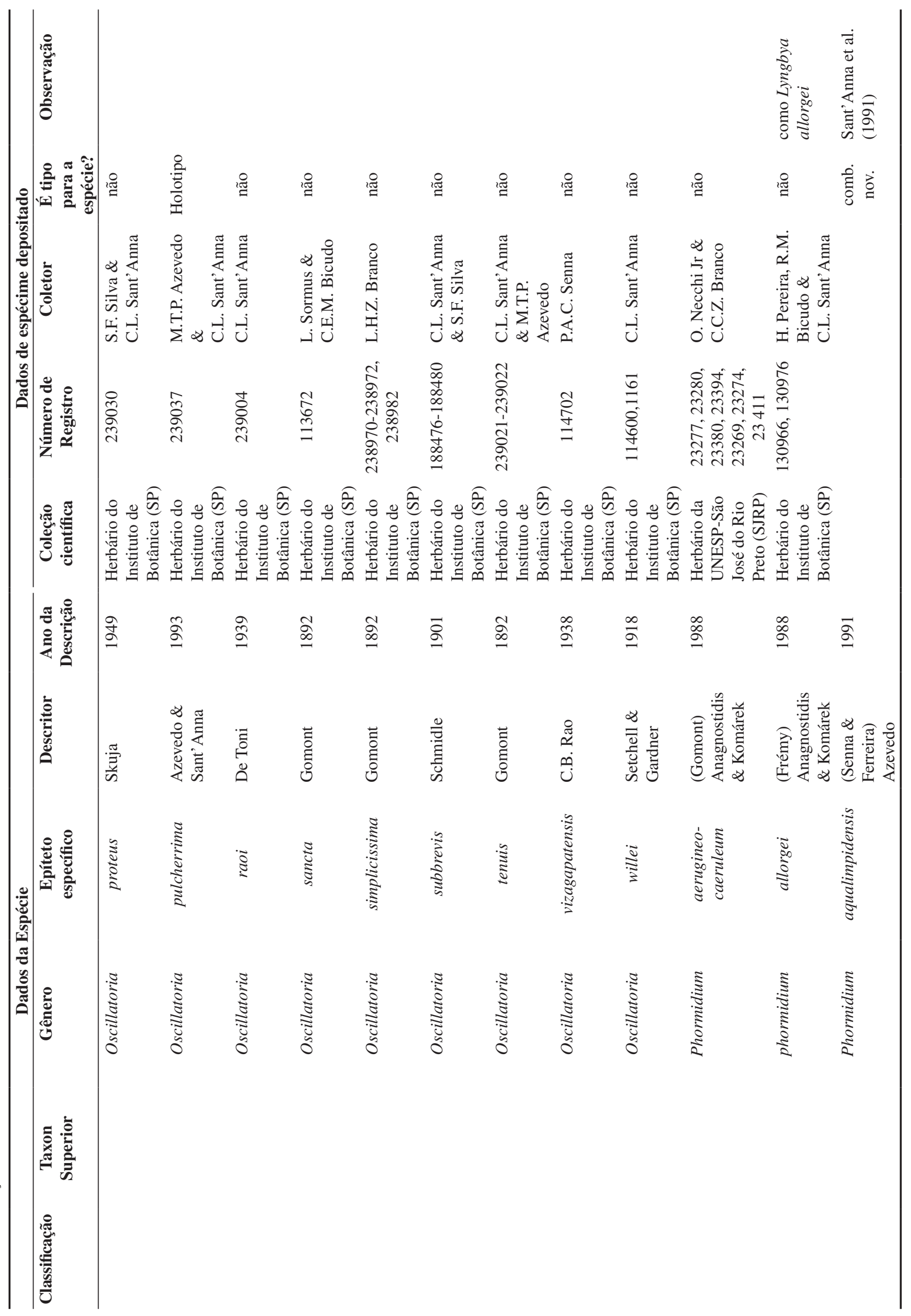


Sant'anna, C.L. et al.

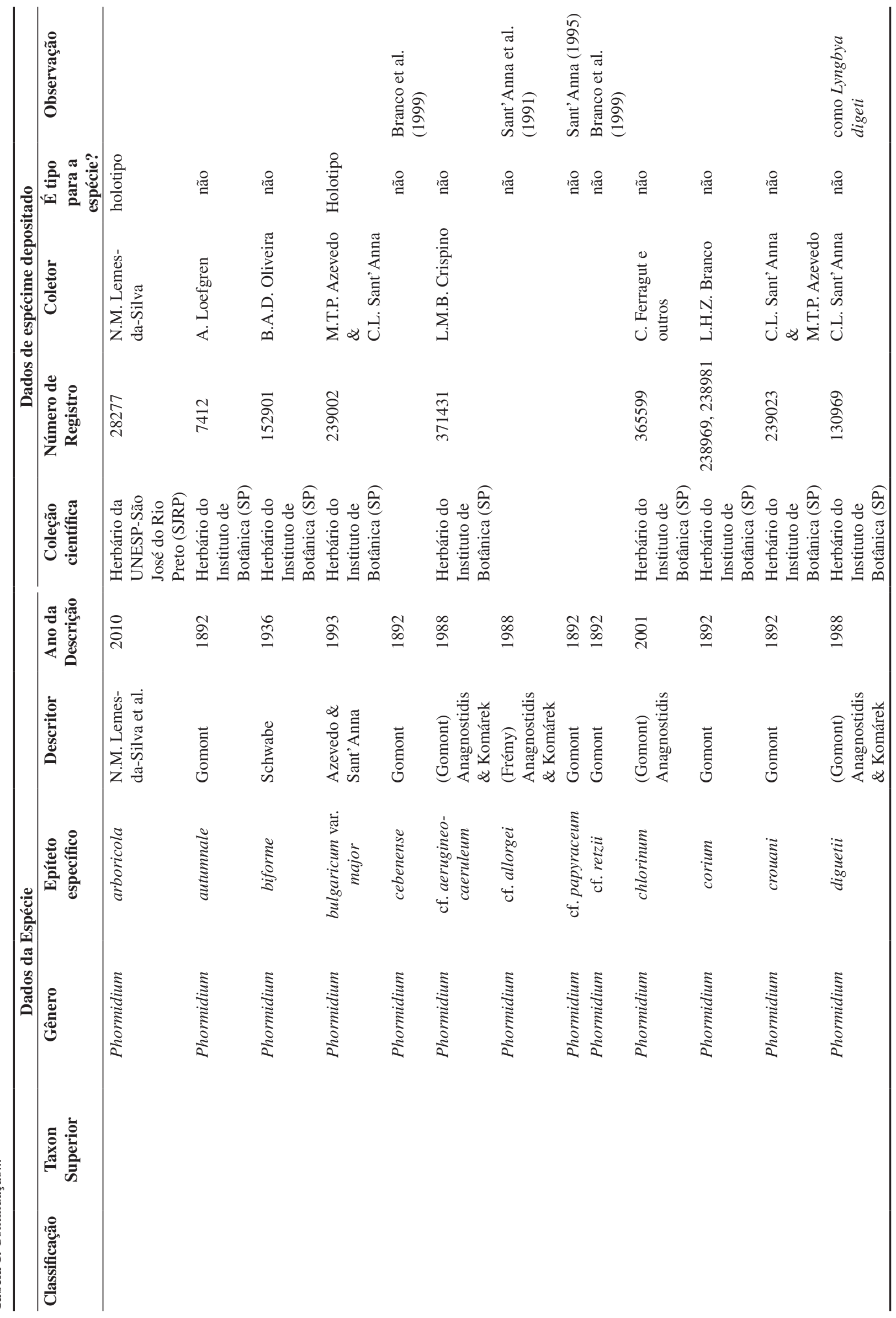


Lista de Cyanobacteria do Estado de São Paulo

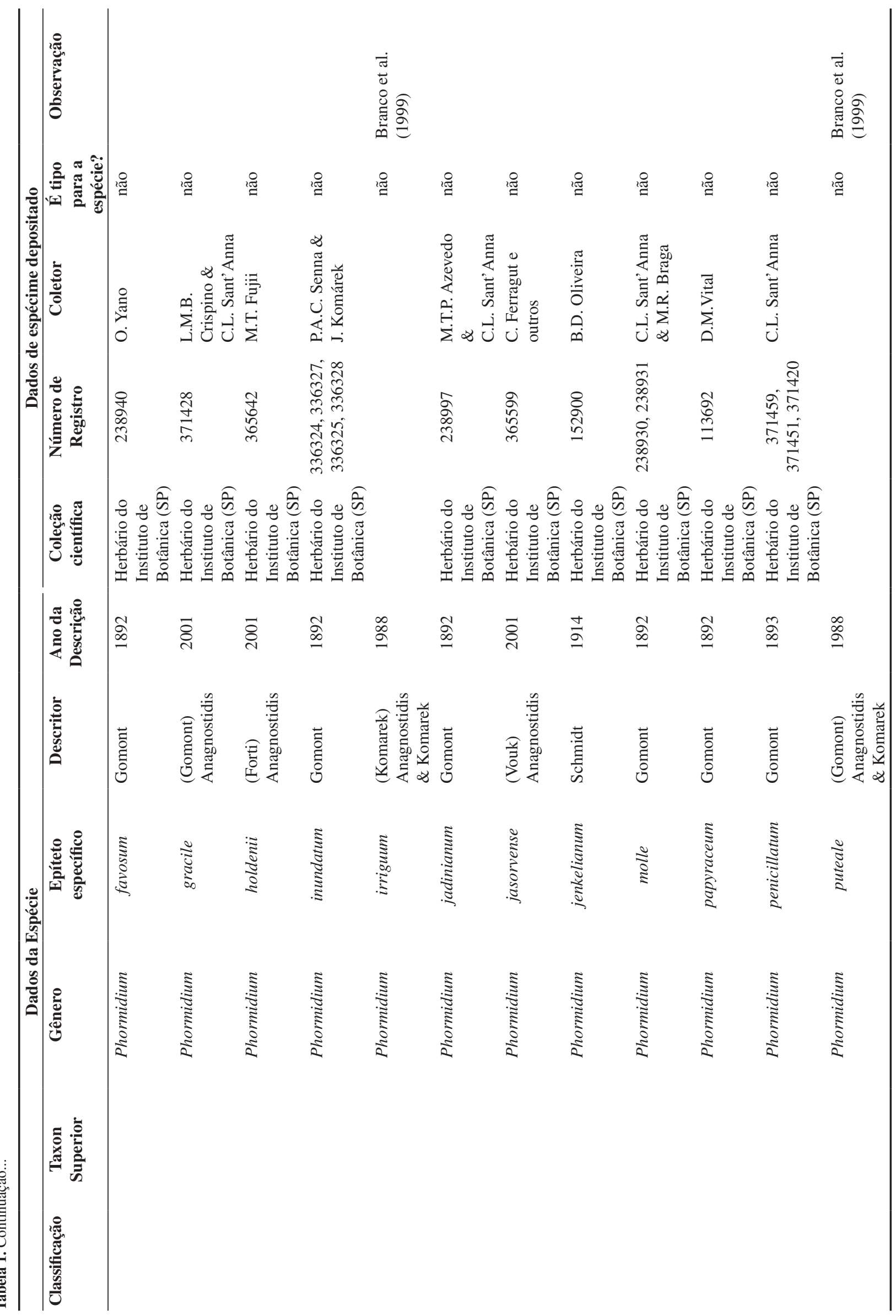


Sant'anna, C.L. et al.

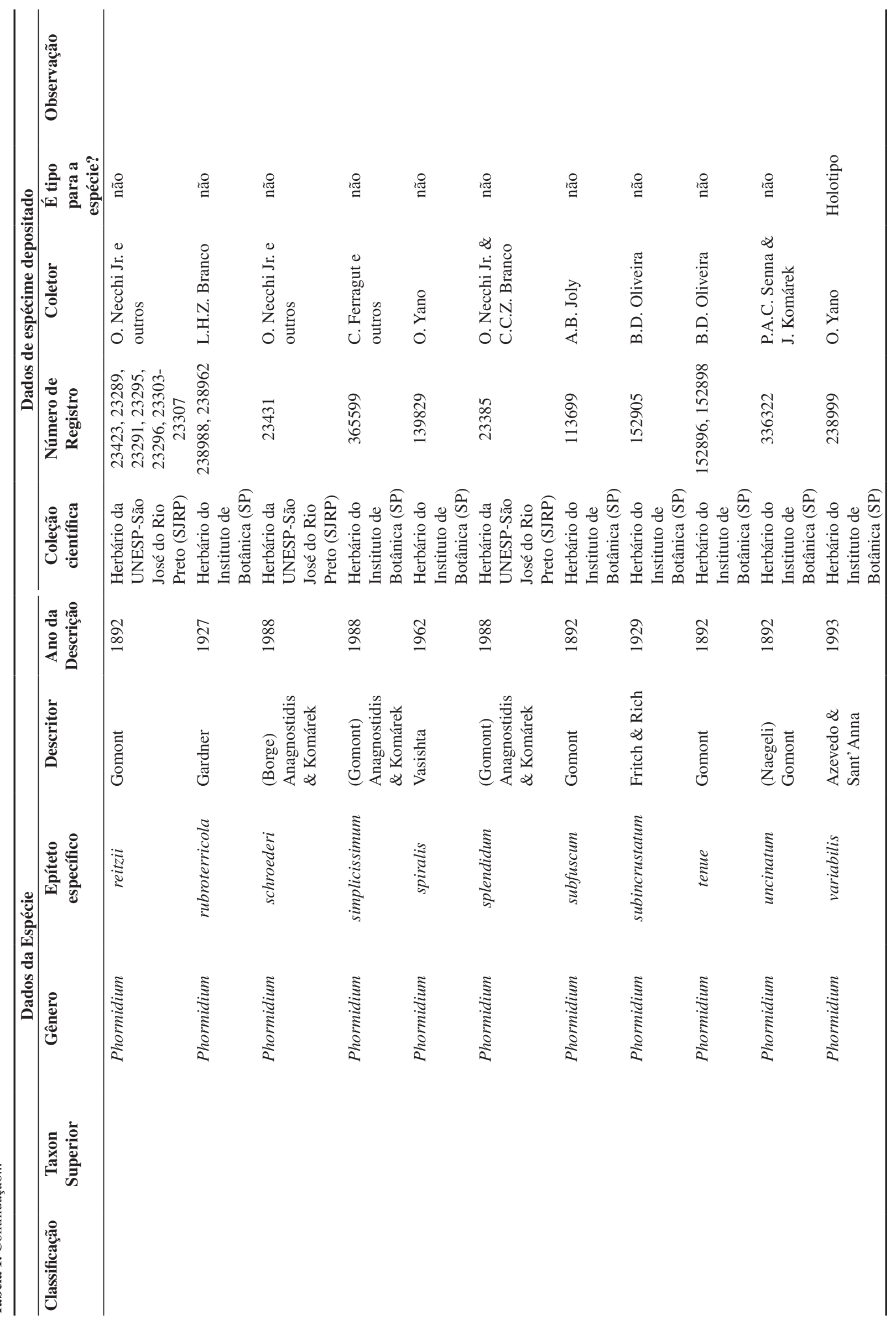




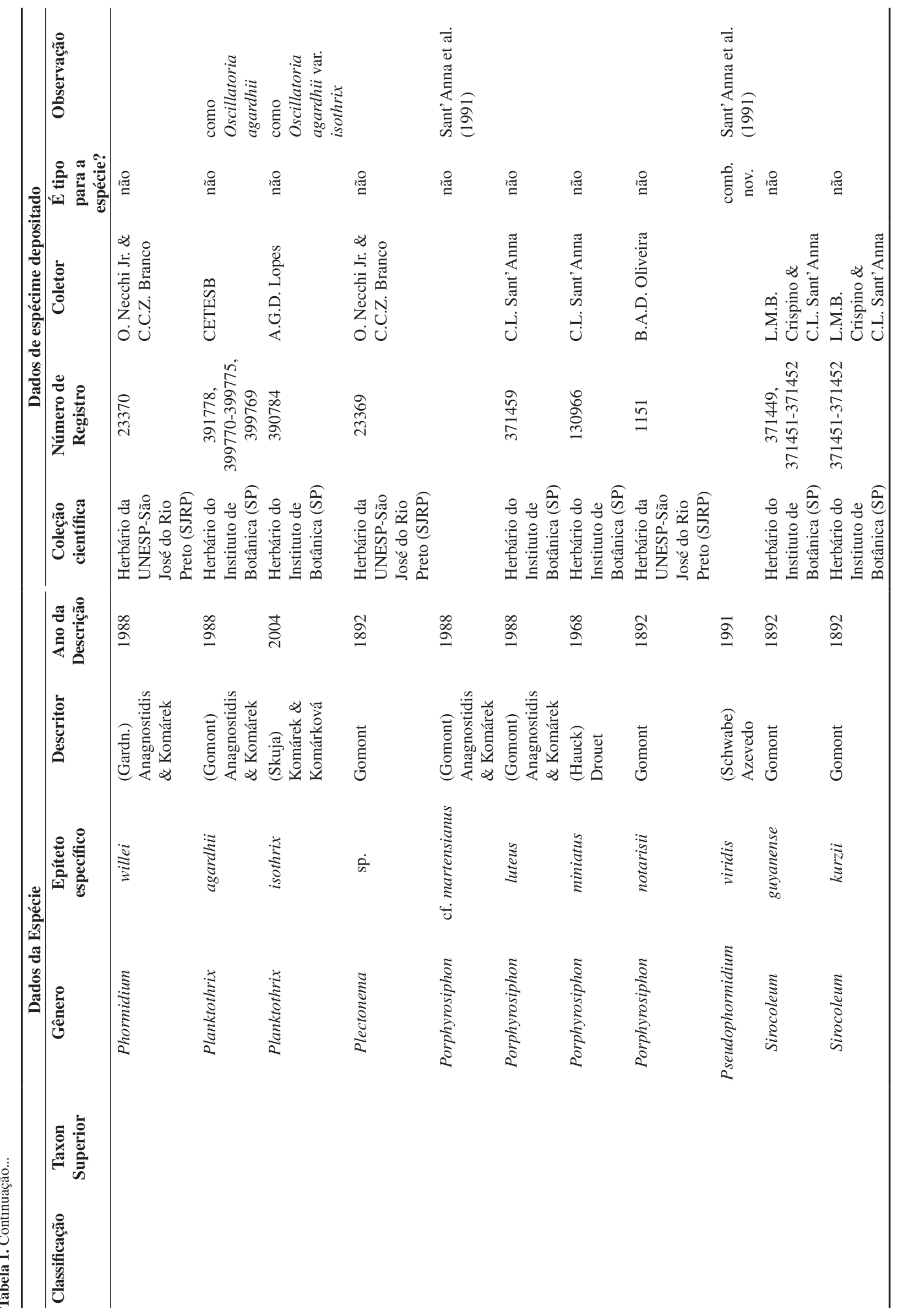


Sant'anna, C.L. et al.

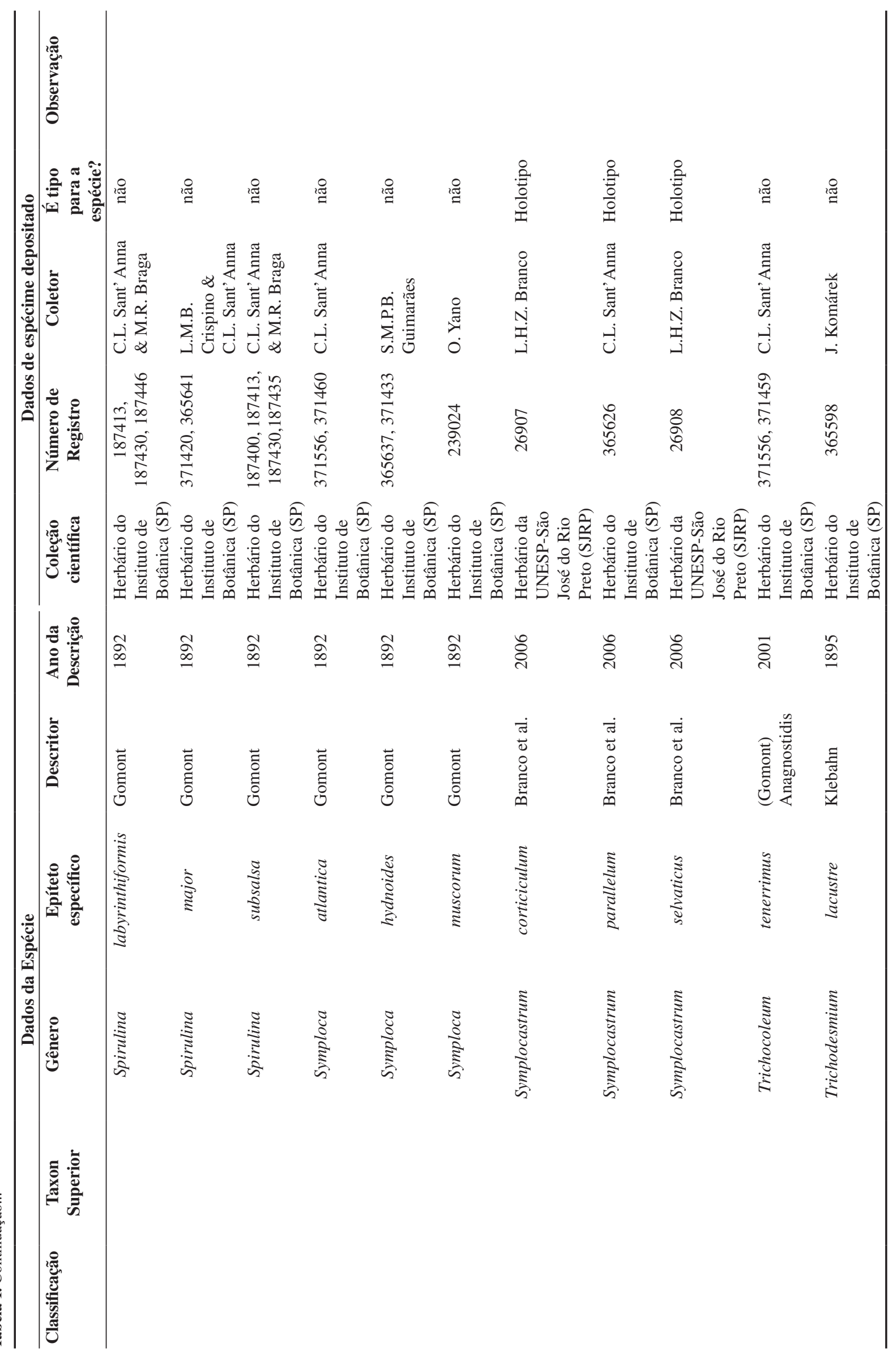




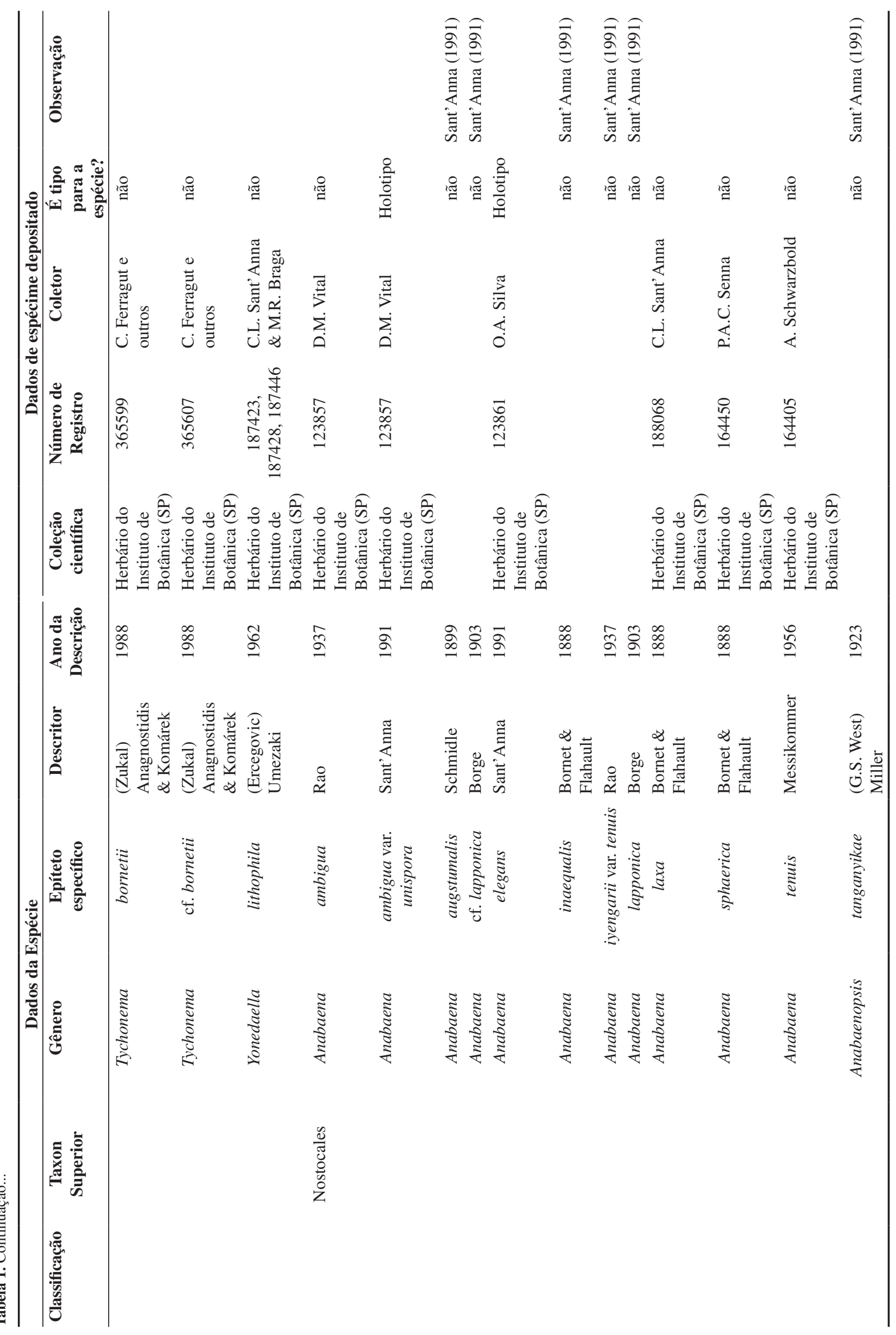




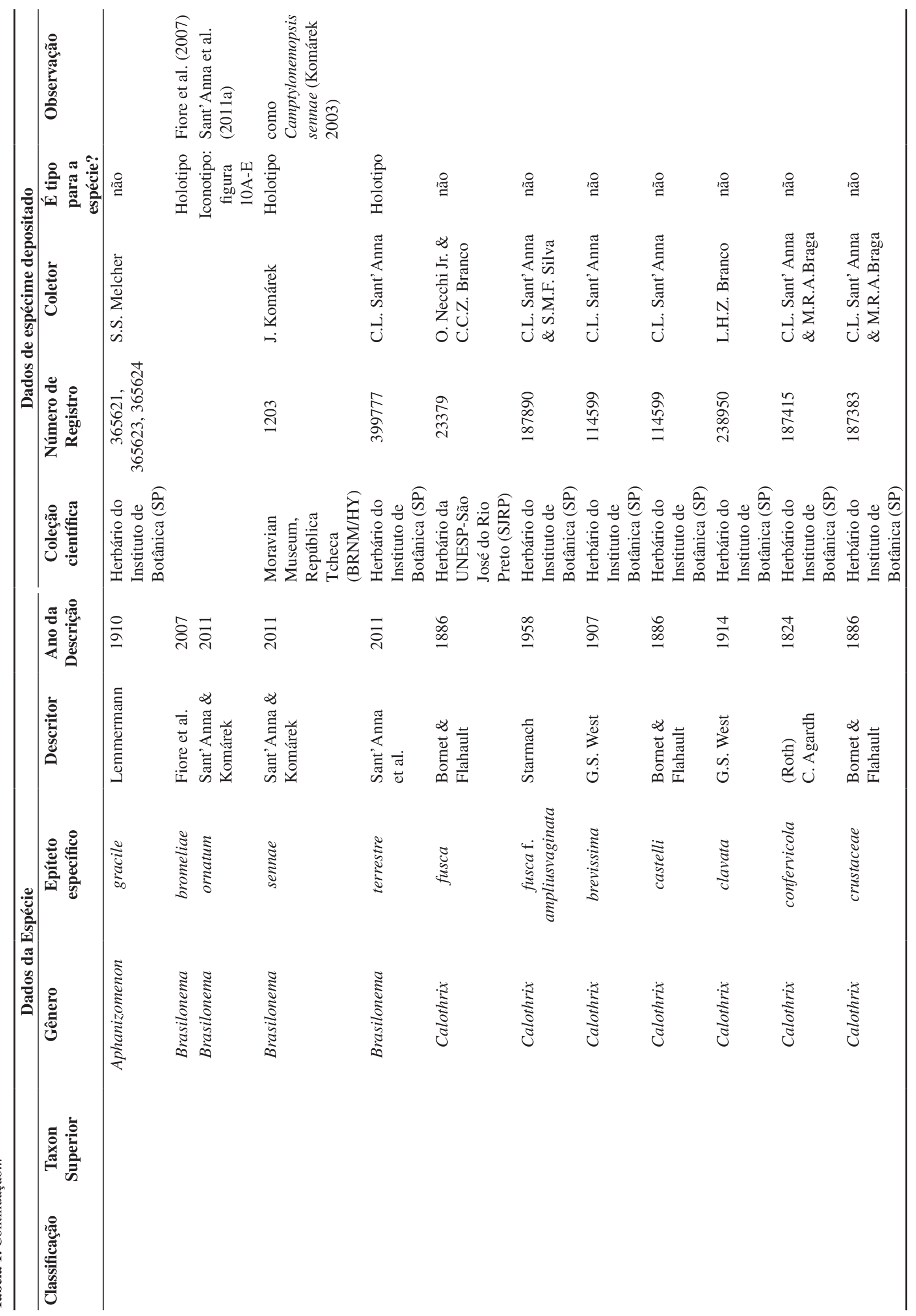




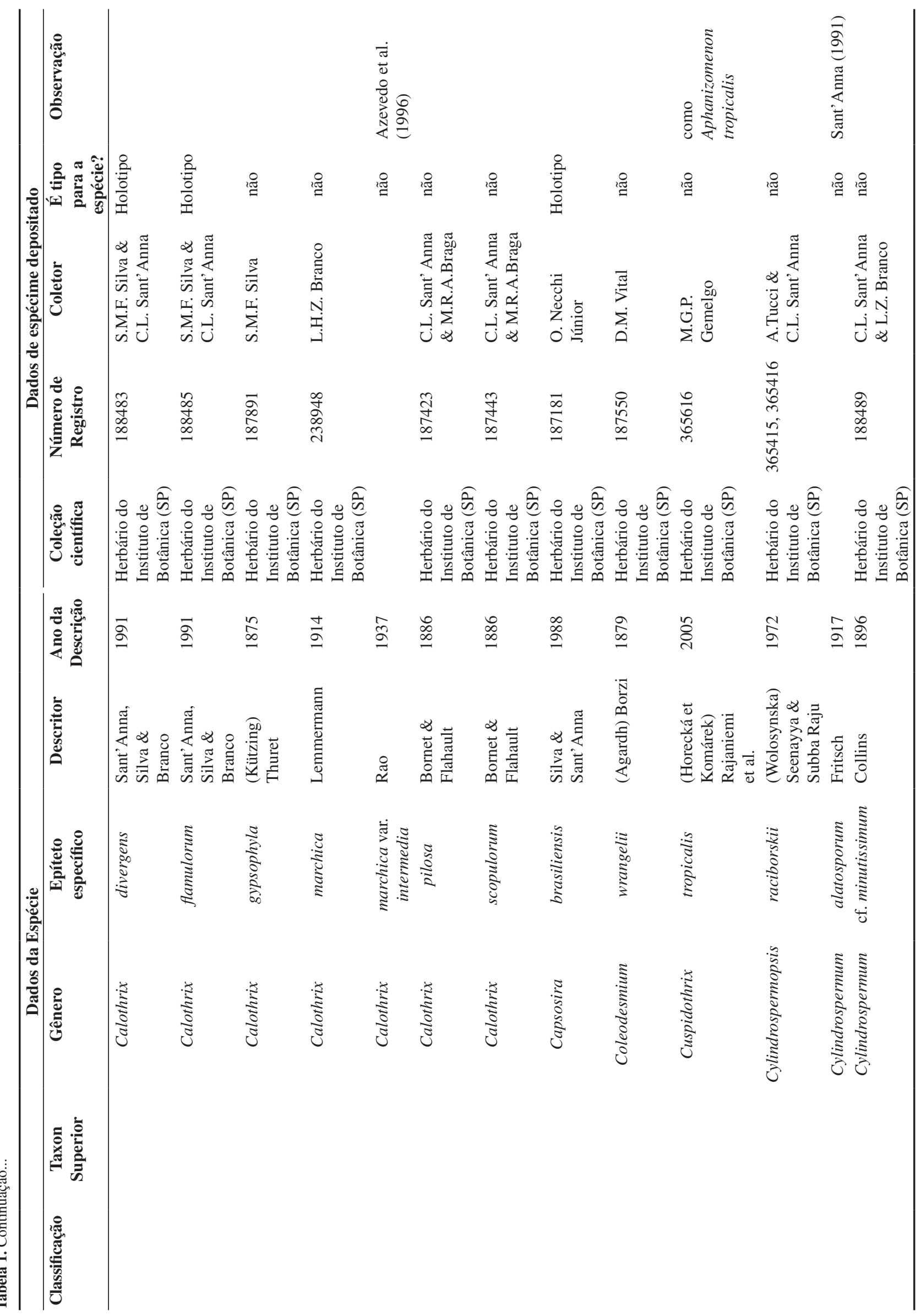


Sant'anna, C.L. et al.

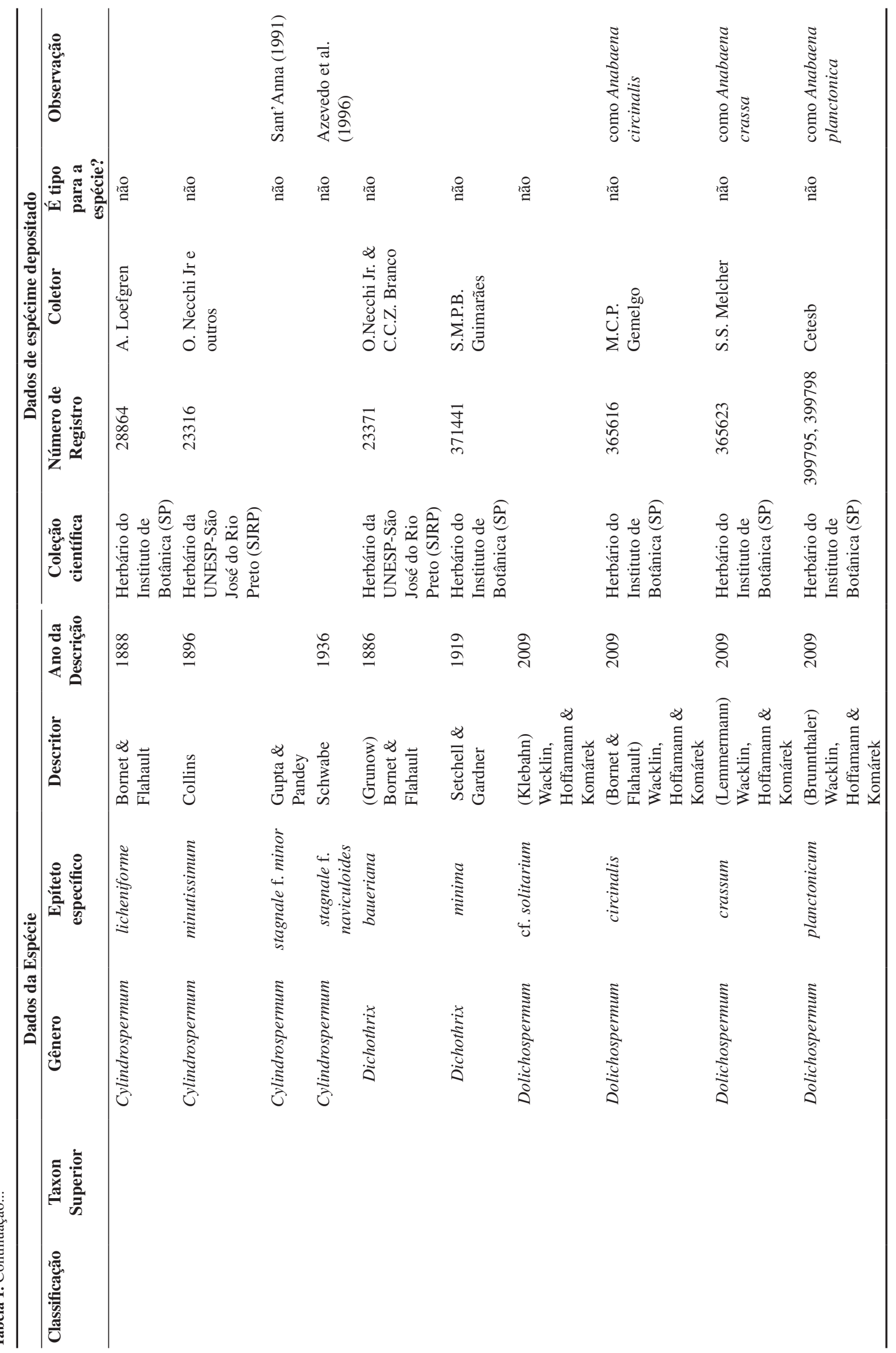




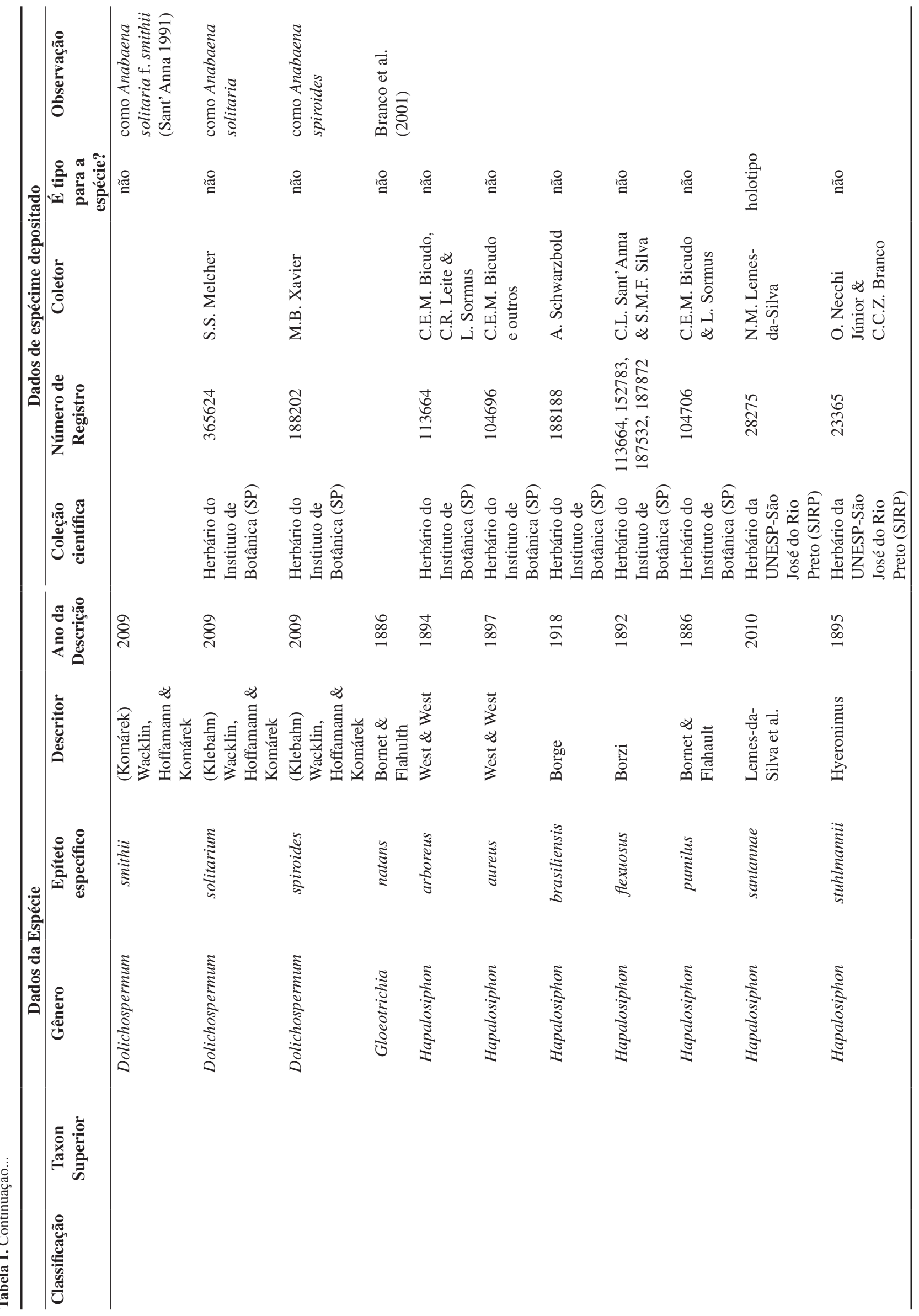



$\mid$\begin{tabular}{l|l} 
\\
|
\end{tabular}

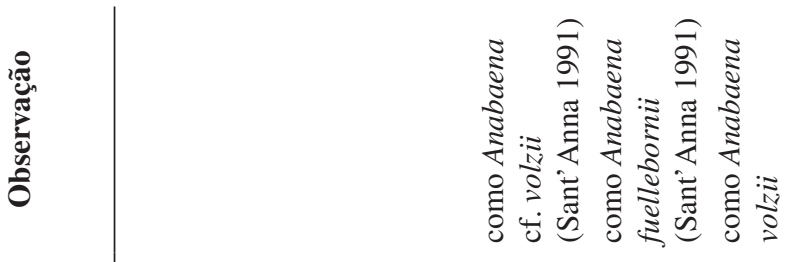

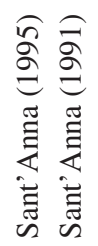

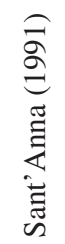

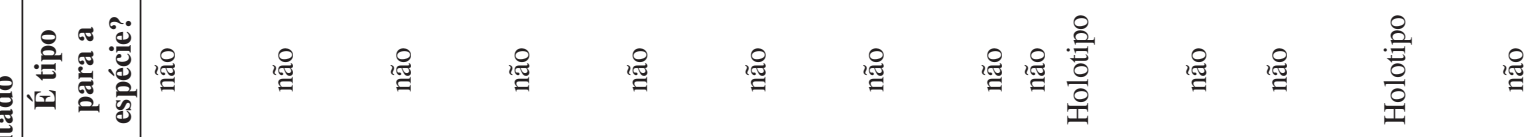
के

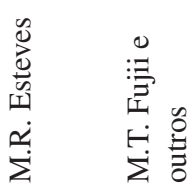

:

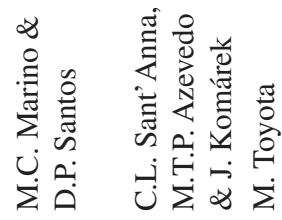

$\begin{array}{ll}\infty & \stackrel{0}{0} \\ \infty & 0 \\ \infty & 0 \\ \infty & \end{array}$

유.

$\begin{array}{lll}\stackrel{1}{+} & \stackrel{0}{0} & \text { i⿱ } \\ \infty & \stackrel{n}{0} & \text { J } \\ \infty & & \end{array}$

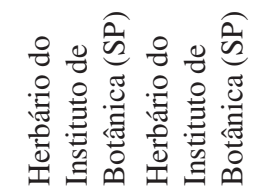
$\because \approx \widetilde{\hat{E}}$

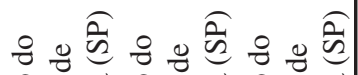

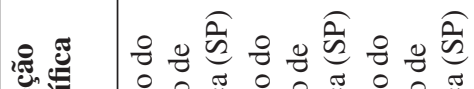

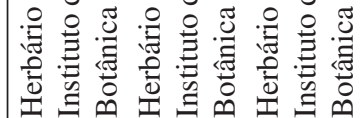

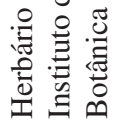

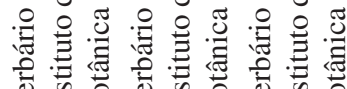

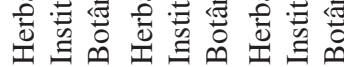

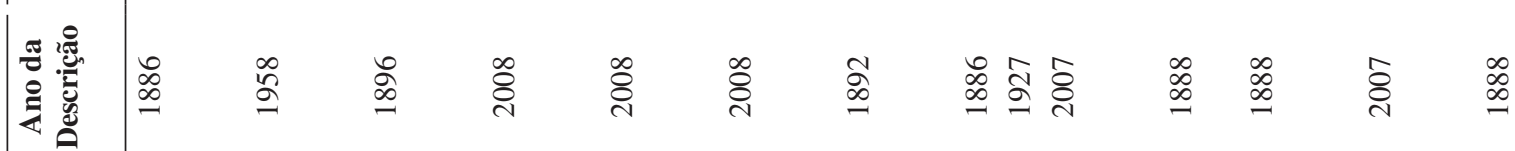

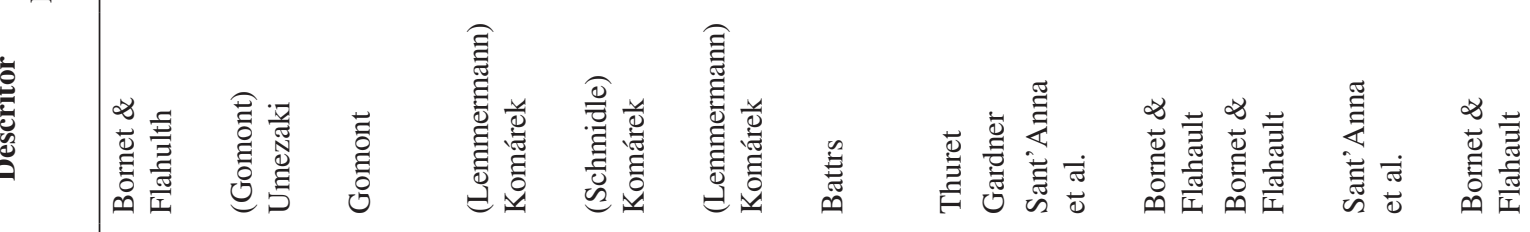

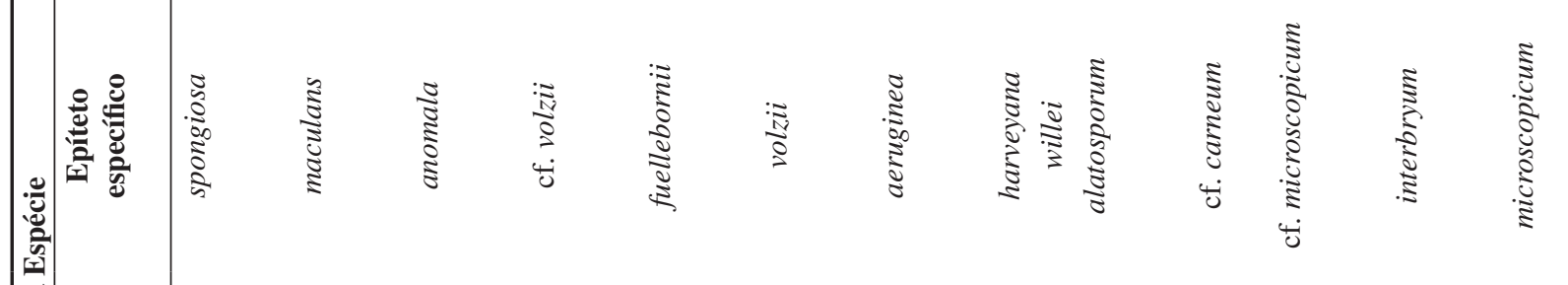

高 


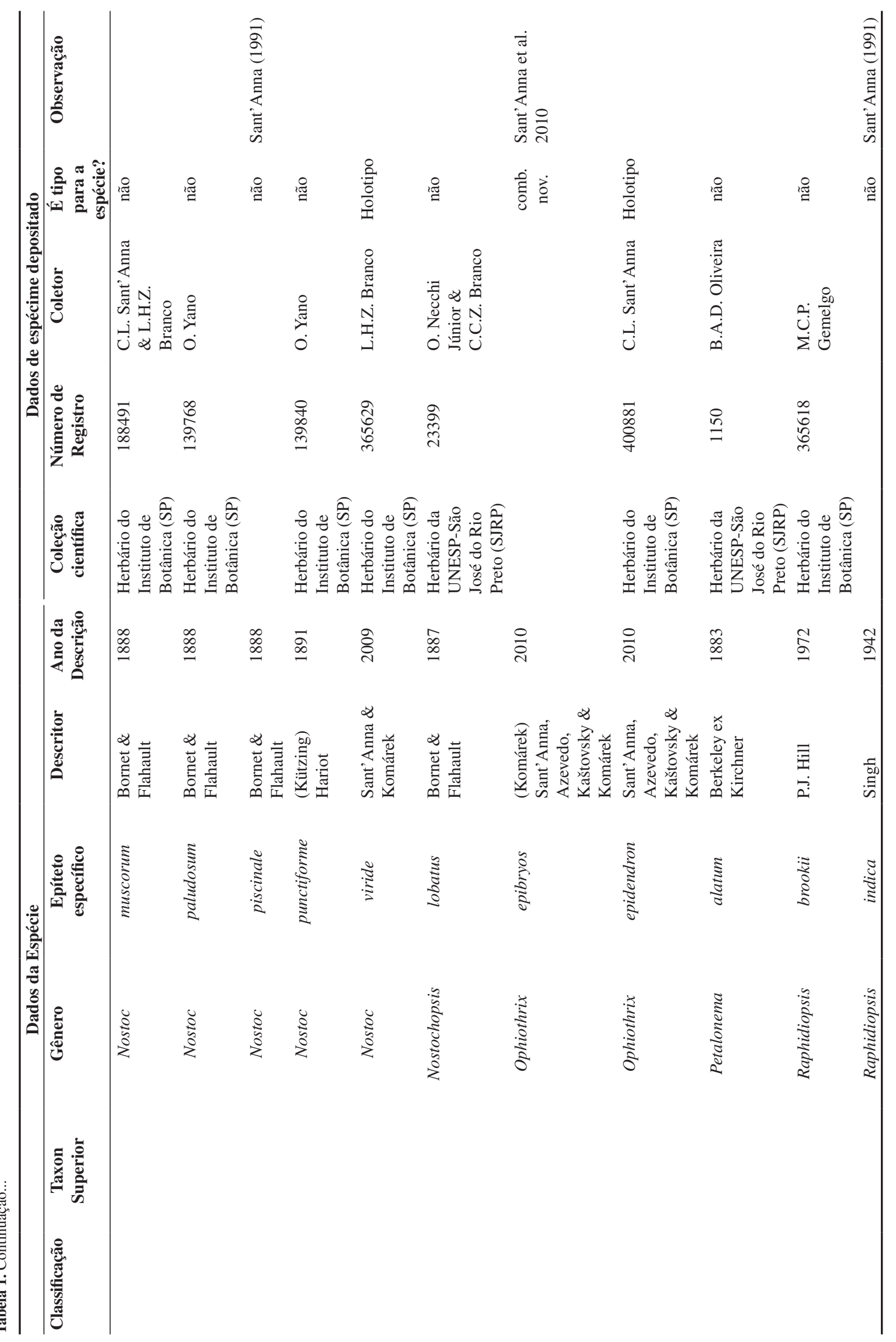


Sant'anna, C.L. et al.

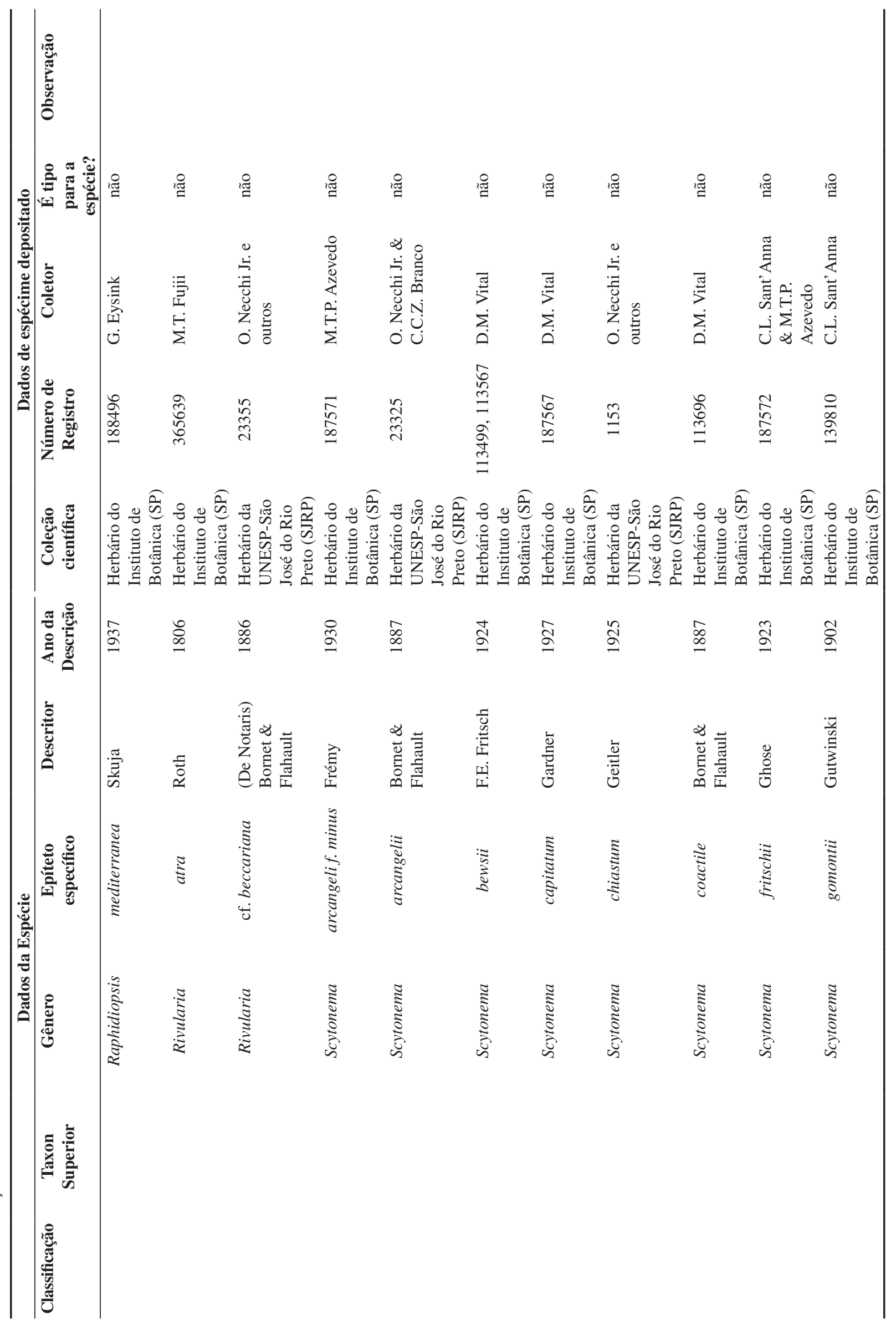


Lista de Cyanobacteria do Estado de São Paulo

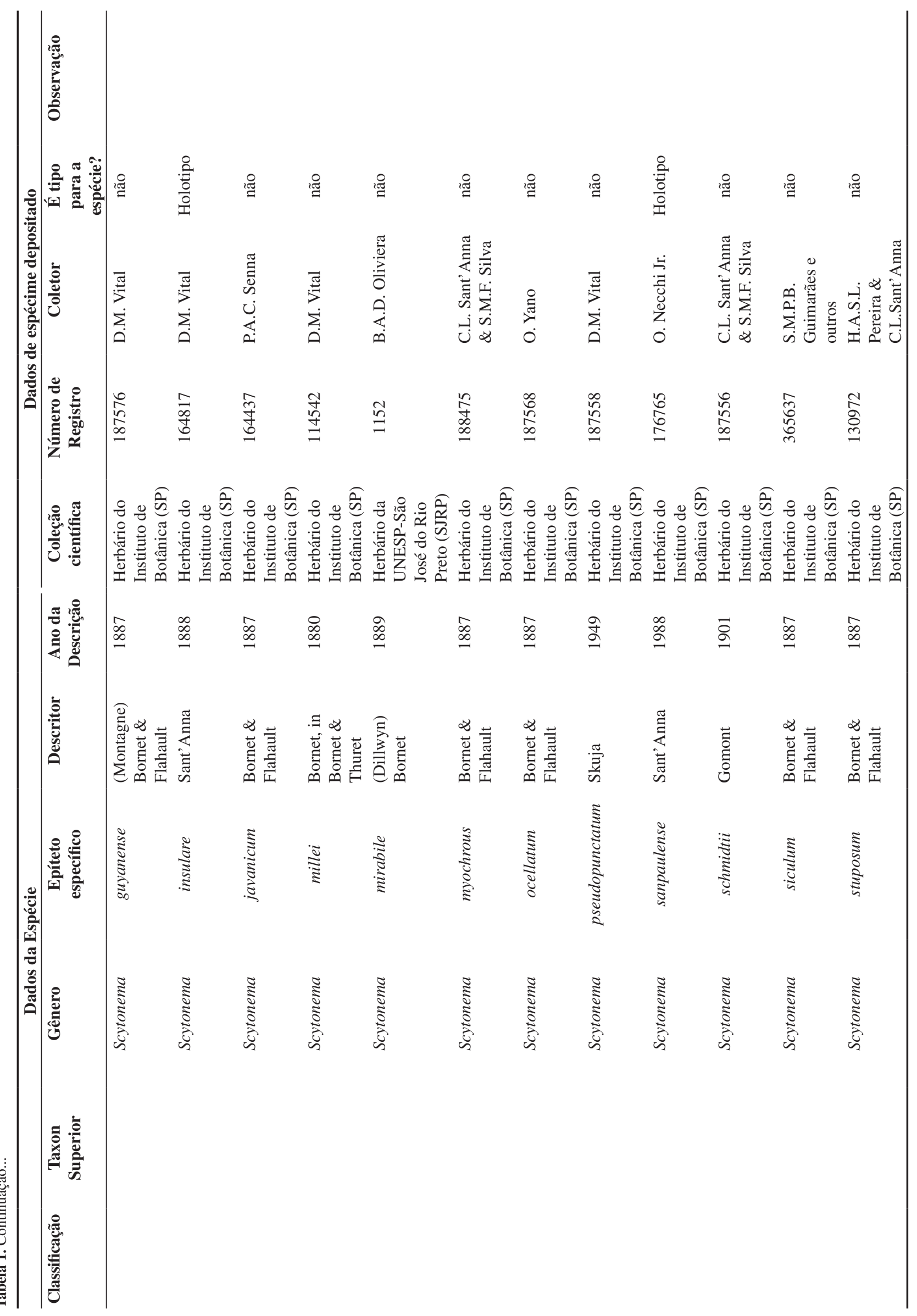




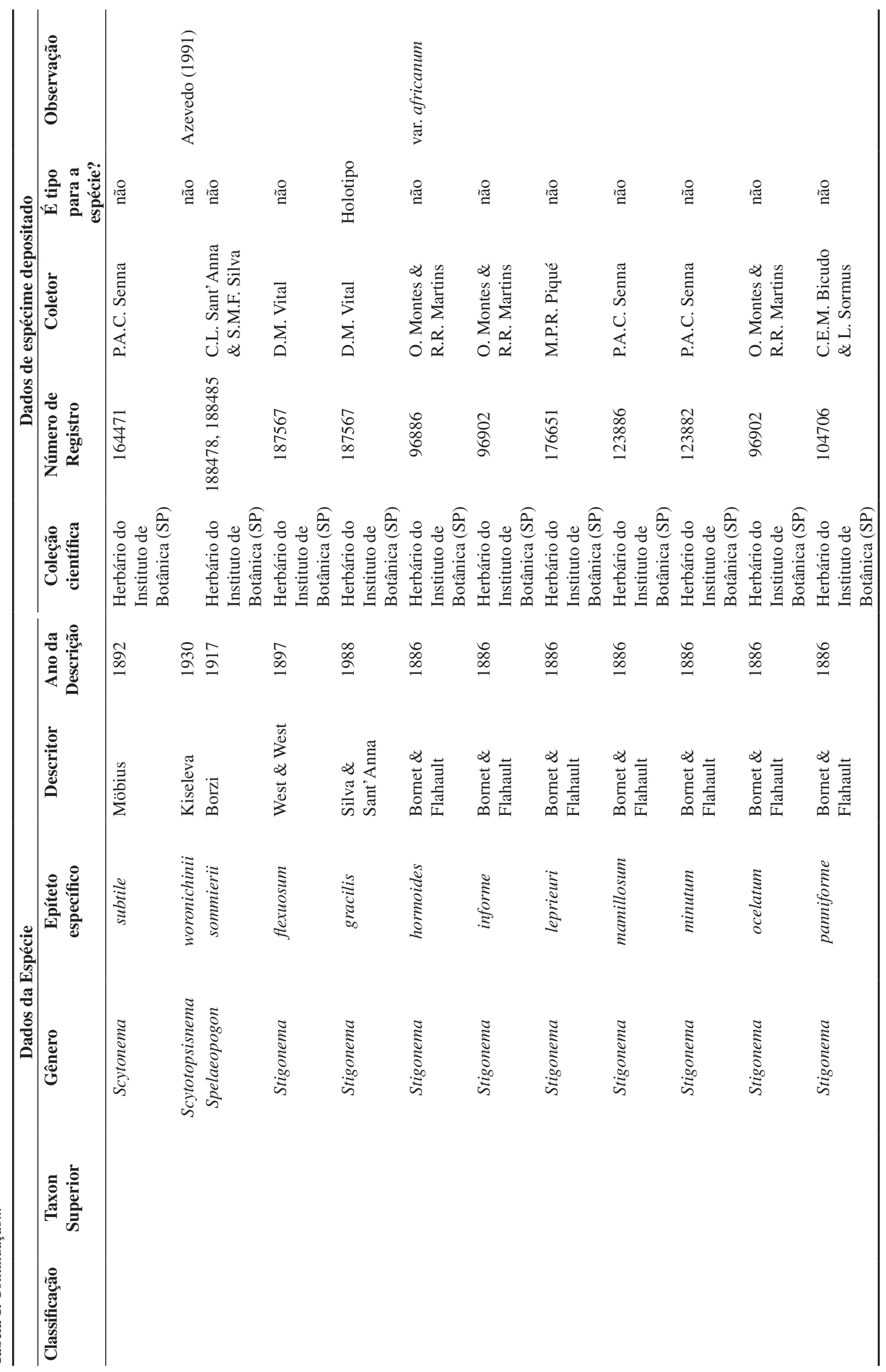




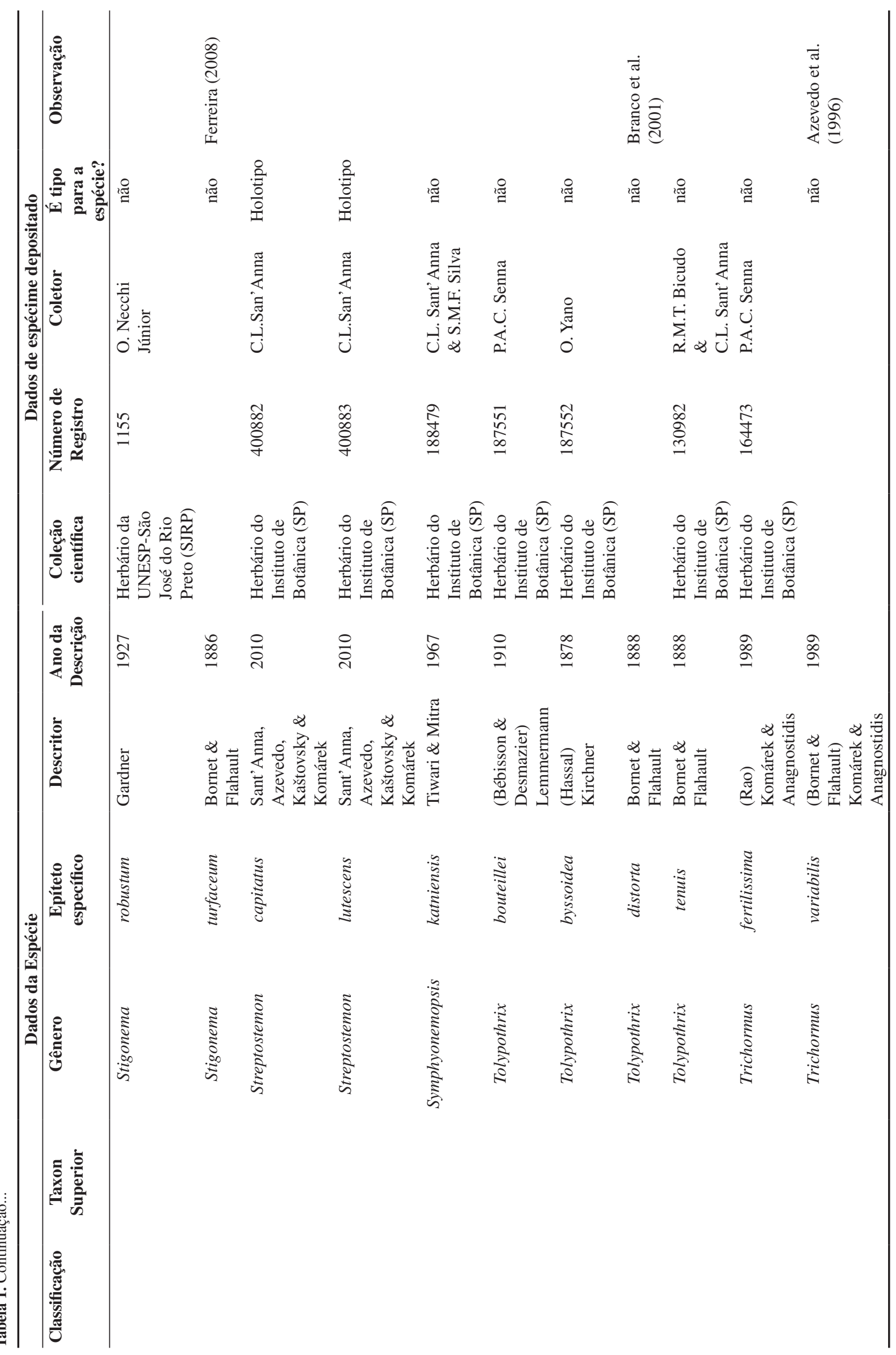


São Paulo, o que corresponde respectivamente a $16 \%$ e $13 \%$ do total de cianobactérias conhecidas. Mesmo levando em conta que das 2800 espécies mencionadas, muitas devem ser sinônimos de outras e que muitas devem ocorrer somente em regiões temperadas, ainda continuamos com pouco conhecimento sobre a riqueza de espécies das cianobactérias brasileiras.

Uma análise mais detalhada da lista de espécies nos mostra que existem 945 registros de ocorrências de cianobactérias no Estado de São Paulo e que a maioria deles refere-se a ambientes aquáticos de água doce, deixando claro que os ecossistemas marinhos e terrestres continuam muito pouco conhecidos. Certamente, grande parte dessa biodiversidade ainda desconhecida concentra-se nestes ambientes pouco estudados, fato amplamente demonstrado pela literatura brasileira mais recente (Branco et al. 2006a,b, Sant'Anna et al. 2011a). Essa disparidade no conhecimento da flora de cianobactérias de água doce em relação aos demais ambientes deve-se em grande parte ao interesse causado pelas espécies planctônicas capazes de produzir toxinas. Estas espécies vêm sendo intensamente estudadas no Brasil e no mundo, pois tem papel ecológico muito importante, além de representarem riscos para a saúde pública quando se trata de reservatórios de abastecimento da população.

Ainda com base na lista de espécies, constatamos um avanço nos estudos florísticos de cianobactérias no Estado. Dos 258 gêneros de cianobactérias aceitos atualmente (Komárek \& Hauer 2011), até 2006, apenas 96 haviam sido citados para o Brasil (Sant'Anna et al. 2006) e agora em 2011, já são 117 gêneros citados para o estado de São Paulo, sendo 35 de Nostocales, 33 de Oscillatoriales/ Pseudanabaenales e 49 de Chroococcales/Synechococcales. A maioria das 378 espécies citadas para o estado pertence ao grupo das filamentosas homocitadas (154), cujos representantes são as ordens Oscillatoriales e Psedanabaenales, seguida das cianobactérias cocóides (Chroococcales e Synechococcales) com 119 espécies e das Nostocales com 105 espécies.

Alguns grupos de Nostocales, que são as cianobactérias heterocitadas e que formam um agrupamento extremamente coeso em termos filogenéticos, apresentam distribuição peculiar no Estado de São Paulo. Os gêneros com ramificação verdadeira (antiga ordem Stigonematales) são apenas sete no Estado e quase todos com uma única espécie, exceto Stigonema que apresenta 11 e Hapalosiphon sete espécies (Lemes-da-Silva et al. 2010, Sant'Anna \& Silva 1988, Silva 1987, Silva \& Sant'Anna 1988). Estes resultados nos levam ao seguinte questionamento: o grupo é raro no estado de São Paulo ou os ambientes onde ocorrem são pouco estudados? De fato, os gêneros com ramificação verdadeira não apresentam grande número de espécies, mas certamente os resultados seriam bem diferentes se os seus ambientes (terrestres) fossem mais explorados em termos de biodiversidade. Além disso, muitos representantes desse grupo ocorrem somente em locais protegidos como florestas, cachoeiras e cavernas e, como se sabe, tais ambientes vêm sendo sistematicamente destruídos ou alterados pelo homem.

As demais Nostocales, isto é os grupos sem ramificação ou apenas com falsas ramificações, apresentam muitos registros de organismos planctônicos ou perifíticos, tais como dos gêneros Anabaena, Anabaenopsis, Aphanizomenon, Cylindrospermopsis, Dolychospermum, Scytonema e Calothrix, que são mais bem estudados no Brasil como um todo. Estes dois últimos são os gêneros de Nostocales com maior número de espécies no Estado: 21 e 14 espécies, respectivamente. Até o momento, é dentro do grupo das cianobactérias com falsas ramificações que se encontra o maior número de gêneros e espécies novos para a ciência com base em material coletado no estado, todos de ambientes terrestres: três gêneros (Brasilonema Fiore et al., Streptostemon Sant'Anna et al. e Ophiothrix Sant'Anna et al.) e 16 novas espécies.
As cianobactérias cocóides estão representadas no Estado por 49 gêneros e 119 espécies. Os gêneros com espécies planctônicas são os que apresentam maior número de ocorrências: Microcystis, Aphanothece, Aphanocapsa e Chroococcus. Os três últimos apresentam os maiores números de espécies no Estado: 15, 10 e 10, respectivamente. Microcystis, pelo fato de apresentar várias espécies formadoras de florações e produtoras de toxinas, é um dos gêneros de cianobactérias mais bem estudados no Estado e, consequentemente, com maior número de registros (33). Para o estado de São Paulo, um gênero novo (Sphaerocavum Azevedo \& Sant'Anna) e 19 espécies novas para a ciência foram descritos. Observou-se que gêneros tipicamente com reprodução por baeócitos e exósporos possuem poucos registros em relação às cianobactérias que se reproduzem exclusivamente por fissão binária. É interessante que Stichosiphon mangle Branco et al. e Chamaesiphon stratosus Sant'Anna et al., que são duas das espécies novas descritas para o Estado de São Paulo, se reproduzem tipicamente por exósporos. Além dessas, algumas Chroococcales que raramente são citadas na literatura possuem espécies descritas para o Estado, como Asterocapsa submersa Azevedo et al. (Azevedo et al. 1996) e Cyanoarbor violascens Branco (Branco et al. 2006). É possível que essas espécies sejam mais bem distribuídas, mas a escassez de estudos em seus ambientes (terrestres e marinhos) não permitiu ainda avaliar a real distribuição geográfica destes grupos no Estado.

Em conjunto, os grupos filamentosos homocitados (Oscillatoriales e Pseudanabaenales) são os maiores em números de espécies (154) no Estado. Os gêneros Phormidium e Oscillatoria são os mais representativos em termos de riqueza de espécies (39 e 30, respectivamente) e, diferentemente do observado em outros grupos, estes gêneros não são planctônicos e sim das comunidades bentônicas ou terrestres. Por outro lado, refletindo os estudos mais intensos nas comunidades planctônicas, Planktothrix (Silva 2009) apresenta grande número de registros (28), embora tenha apenas duas espécies citadas para o Estado. Assim como constatamos para as demais ordens de cianobactérias, são nos ambientes terrestres que encontramos a maior parte das nove espécies novas de Oscillatoriales descritas com base em amostras do Estado. Provavelmente, a riqueza de espécies das cianobactérias homocitadas está muito subestimada, pois ao elaborarmos a presente lista, verificamos que diversos materiais não puderam ser incluídos porque não tinham identificação de espécie. Como estas cianobactérias são constituídas de filamentos simples e comumente com grande variabilidade morfológica, a identificação específica e mesmo genérica torna-se bem mais difícil.

Agravando o problema dos estudos de biodiversidade de cianobactérias em geral temos ainda a insuficiência de literatura especializada sobre a flora de regiões tropicais/subtropicais, o que evitaria comparações inapropriadas com material de regiões temperadas e erros grosseiros de identificação.

\section{Principais avanços relacionados ao Programa Biota}

O Programa Biota teve grande influência no atual nível do conhecimento sobre a biodiversidade de cianobactérias do estado de São Paulo, sobretudo com relação aos intensivos esforços de coleta em todo o estado, incluindo a região litorânea e ambientes terrestres que até então eram extremamente mal conhecidos. Além disso, as bolsas para estudantes têm sido fundamentais para que o conhecimento dessa biodiversidade avance e novos aspectos da pesquisa possam ser desenvolvidos, como estudos moleculares e busca por produtos com atividades biológicas.

As comunidades de cianobactérias marinhas bentônicas tiveram um aumento de $20 \%$ no conhecimento da sua riqueza de espécies (Crispino 2007, Crispino \& Sant'Anna 2006), graças às coletas realizadas a partir de 2000, dentro do Programa Biota. O mesmo 
pode-se dizer em relação aos ambientes terrestres, sobretudo em áreas da Mata Atlântica, onde estão sendo descritos vários novos gêneros e espécies em todos os grupos de cianobactérias.

Outro aspecto muito importante trazido pelo Programa Biota é a organização das coleções biológicas em bancos de dados como o SpeciesLink que fornecem subsídios para diversos tipos de pesquisa.

\section{Principais grupos de pesquisa}

No Núcleo de Pesquisas em Ficologia do Instituto de Botânica de São Paulo (IBt) está o principal grupo que se dedica ao estudo das cianobactérias no estado de São Paulo. Na entidade são realizados estudos taxonômicos, ecológicos, bioquímicos, toxicológicos e biotecnológicos envolvendo cianobactérias planctônicas de águas continentais, além de ambientes marinhos e terrestres. O Instituto de Botânica possui uma coleção de culturas de cianobactérias com 420 cepas isoladas principalmente de diferentes regiões do Estado de São Paulo. As Dras. Célia Leite Sant'Anna, Luciana Retz de Carvalho, Maria Teresa de Paiva Azevedo e Andréa Tucci integram o grupo, além de diversos estudantes de graduação e pós-graduação. Ainda no Instituto de Botânica, estudos enfocando aspectos ecológicos das cianobactérias são desenvolvidos no Núcleo de Pesquisas em Ecologia e conduzidos pelos Drs. Carlos Eduardo de Mattos Bicudo, Denise de Campos Bicudo e Carla Ferragut.

No Laboratório de Ficologia do Departamento de Zoologia e Botânica da UNESP, campus de São José do Rio Preto, o grupo liderado pelo Dr. Luis Henrique Zanini Branco tem desenvolvido estudos taxonômicos e moleculares enfocando principalmente as cianobactérias aerofíticas provenientes de diferentes tipos de habitat. O grupo tem se dedicado também aos levantamentos florísticos de comunidades de cianobactérias de ambientes lóticos, além de aspectos da distribuição ecológica dos organismos estudados.

A Dra. Marli de Fátima Fiore e seu grupo de pesquisa, do Centro de Energia Nuclear na Agricultura (CENA) do campus de Piracicaba da USP, têm desenvolvido trabalhos voltados à sistemática e filogenia de cianobactérias utilizando técnicas moleculares, bem como têm abordado as propriedades químicas de compostos extraídos de cianobactérias. O grupo tem ainda desenvolvido trabalhos sobre cianotoxinas e os genes envolvidos na sua produção.

No Laboratório de Cianobactérias, da Escola Superior de Agricultura "Luiz de Queiroz" (ESALQ, USP, Piracicaba) são desenvolvidas atividades de pesquisa com cianobactérias, tendo ênfase nas espécies produtoras de toxinas e enfocando aspectos filogenéticos, taxonômicos, toxicológicos e ecofisiológicos. O laboratório possui também um banco de culturas de cianobactérias. O grupo é liderado pela Dra. Maria do Carmo Bittencourt Oliveira e conta também com alunos de graduação e pós-graduação.

\section{Principais acervos}

No estado de São Paulo existem apenas dois herbários organizados que possuem cianobactérias entre os espécimes arquivados.

O principal acervo que contém exemplares de cianobactérias é o Herbário "Maria Eneida P. Kauffman Fidalgo" do Instituto de Botânica de São Paulo e cujo acrônimo é SP. Reúne aproximadamente 1500 registros de cianobactérias brasileiras de ambientes aquáticos e terrestres, sendo que cerca de 750 amostras são provenientes de diferentes habitats e localidades do estado de São Paulo. O Curador dessa coleção é a Dra. Célia Leite Sant'Anna.

O Herbário da UNESP-campus de São José do Rio Preto, registrado sob o acrônimo SJRP, abriga cerca de 70 amostras de cianobactérias, principalmente provenientes de ambientes lóticos do estado de São Paulo, mas possui também material de ambientes terrestres. Os principais incentivadores dessa coleção em termos de coleta e identificação de material são os Drs. Luis H.Z. Branco e Orlando Necchi Jr.

\section{Principais lacunas do conhecimento}

Embora as cianobactérias tenham recebido mais atenção nos últimos anos, ainda há necessidade de levantamentos mais detalhados em determinadas regiões do estado, como, por exemplo, a oeste/ sudoeste, nas imediações do Pontal do Paranapanema, onde há poucos estudos realizados. Do mesmo modo, as comunidades de cianobactérias de alguns ecossistemas, como o cerrado paulista, por exemplo, ainda são pobremente conhecidas e estão em situação de risco devido à fragmentação e deterioração ambiental.

Do ponto de vista dos habitats amostrados, nota-se que o conhecimento da flora de cianobactérias aquáticas (águas doces correntes ou lênticas e marinhas) vem aumentando significativamente há vários anos. As comunidades aerofíticas/terrestres, contudo, ainda não são suficientemente amostradas e conhecidas. Estas constituem um enfoque importante para estudos futuros em biodiversidade, uma vez que os trabalhos realizados nesses habitats têm revelado novos registros de ocorrência no estado e, até mesmo, de novos gêneros e espécies para a Ciência.

Os ambientes marinhos também devem ser mais bem detalhados, uma vez que os estudos realizados até o momento são concentrados na região sul do estado e limitam-se, principalmente, à região do supra-litoral. Investigações mais detalhadas em outras localidades e em outras zonas do litoral devem acrescentar novos dados ao contingente de espécies conhecidas no território paulista.

\section{Perspectivas de pesquisa em cianobactérias para os próximos 10 anos}

É possível considerar que, ao longo da próxima década, os estudos sobre a diversidade de cianobactérias realizados na área do Estado terão sido suficientes para registrar cerca de $90 \%$ da flora ocorrente no território. Ao longo desse período, devem ser iniciados/incrementados estudos que utilizem os dados gerados pelo conhecimento da biodiversidade. Trabalhos abordando aspectos da filogenia de grupos específicos deverão ser gradativamente incrementados e incorporarão técnicas modernas de estudo (como biologia molecular e proteômica, por exemplo). Além disso, livros sobre biodiversidade de cianobactérias de regiões tropicais e subtropicais deverão ser publicados.

Devido às características particulares de algumas cianobactérias, é possível considerar que a prospecção de produtos produzidos por esses organismos (como carboidratos, óleos e proteínas) sejam iniciativas bastante desejáveis e promissoras. Os organismos do grupo são capazes de produzir substâncias de interesse biotecnológico e com atividade biológica potencial relevante, como produtos antitumorais, anticolinesterásicos e antifúngicos. Como consequência desses esforços, a caracterização e a produção de compostos de interesses diversos devem ser campos de pesquisa com boas possibilidades em um futuro de médio prazo.

\section{Referências Bibliográficas}

AZEVEDO, M.T.P. 1991. Edaphic blue-green algae from the São Paulo Botanical Garden, Brazil. Algol. Stud. 64:503-526.

AZEVEDO, M.T.P. \& KOVÁČIK, L. 1996. Rhabdogloea brasilica sp. nov. (Chroococcales, Synechococcaceae): morphological and morphometric variability under cross-gradient cultures. Algol. Stud. 83:83-92.

AZEVEDO, M.T.P., NOGUEIRA, N.M.C. \& SANT'ANNA, C.L. 1996. Criptógamas no Parque Estadual das Fontes do Ipiranga, São Paulo, SP. Algas, 8: Cyanophyceae. Hoehnea 23(1):1-38. 
AZEVEDO, M.T.P. \& SANT'ANNA, C.L. 1994. Cyanostylon gelatinosus, a new species (Chroococcales, Cyanophyceae) from São Paulo State, Brazil. Algol. Stud. 75:75-78.

AZEVEDO, M.T.P. \& SANT'ANNA, C.L. 1999. Coelosphaerium evidentermarginatum, a new planktonic species of Cyanophyceae/Cyanobacteria from São Paulo State, Southeastern Brazil. Algol. Stud. 94:35-43.

AZEVEDO, M.T.P. \& SANT'ANNA, C.L. 2003. Sphaerocavum brasiliense, a new planktic genus and species of Cyanobacteria from reservoirs of São Paulo State, Brazil. Algol. Stud. 109:79-92.

AZEVEDO, M.T.P., SANT'ANNA, C.L., SENNA, P.A.C., KOMÁREK, J. \& KOMÁRKOVÁ. 2003. Contribution to the microflora of chroococcalean cyanoprokaryotes from São Paulo State, Southeast Brazil. Hoehnea 30(3):285-295.

BRANCO, L.H.Z., AZEVEDO, M.T.P., Sant'Anna, C.L. \& KOMÁREK, J. 2006a. New morphospecies of Symplocastrum (Phormidiaceae, Oscillatoriales) from aerophytic habitats in Brazil. Algol. Stud. 121:23-33. http://dx.doi.org/10.1127/1864-1318/2006/0121-0023

BRANCO, L.H.Z., HOFFMANN, L., TEIXEIRA, J.P., FERREIRA, V. \& MORAIS FILHO, J.C. 2009. Aerophytic cyanoprokaryotes from the Atlantic rainforest region of São Paulo State, Brazil: Chroococcales and Oscillatoriales. Cryptogam., Algol. 30(1):135-152.

BRANCO, L.H.Z., KOMAREK, J., AZEVEDO, M.T.P., SANT'ANNA, C.L. \& WATANABE, M. 2006. The cyanobacterial genus Cyanoarbor Wang (Chroococcales, Entophysalidaceae) and its occurrence in Brazil. Nova Hedwigia 82:365-380.

BRANCO, L.H.Z., KOMÁREK, J., AZEVEDO, M.T.P., SANT'ANNA, C.L. $\&$ WATANABE, M. 2006b. The cyanobacterial genus Cyanoarbor Wang (Chroococcales, Entophysalidaceae) and its occurrence in Brazil. Nova Hedwigia 82:265-380. http://dx.doi.org/10.1127/0029-5035/2006/00820365

BRANCO, L.H.Z., NECCHI-JUNIOR, O. \& BRANCO, C.C.Z. 1999. Cyanophyceae from lotic ecosystems of São Paulo State, southeastern Brazil. Algol. Stud. 94:63-87.

BRANCO, L.H.Z., NECCHI-JUNIOR, O., BRANCO, C.C.Z. 2001. Ecological distribution of Cyanophyta in lotic ecosystems of São Paulo State. Rev. Bras. Bot. 24:99-108.

BRANCO, L.H.Z., SILVA, S.M.F. \& SANT'ANNA, C.L. 1995. Validation of the name Stichosiphon mangle (Chroococcales, Cyanophyta). Taxon 44:393.

CRISPINO, L.M.B. \& SANT'ANNA, C.L. 2006. Cianobactérias marinhas bentônicas de ilhas costeiras do estado de São Paulo. Rev. Bras. Bot. 29(4):639-656

CRISPINO, L.M.B. 2007. Cianobactérias marinhas bentônicas do litoral do Estado de São Paulo, Brasil. Tese de Doutorado, Instituto de Botânica, São Paulo.

FERREIRA, V. 2008. Flora de Nostocales com ramificações verdadeiras com ênfase em organismos aerofíticos da região de mata atlântica paulista. Dissertação de Mestrado, Universidade Estadual de São Paulo, São José do Rio Preto.

FIORE, M.F., NEILAN, B.A., COPP, J.N., RODRIGUES, J.L.M., TSAI, S.M., LEE, H. \& TREVORS, J.T. 2005. Characterization of nitrogenfixing cyanobacteria in the Brazilian Amazon floodplain. Water Res. 39:5017-5026. PMid:16289234. http://dx.doi.org/10.1016/j. watres.2005.10.002

FIORE, M.F, SANT'ANNA, C.L., AZEVEDO, M.T.P., KOMÁREK, J., KAŠTOVSKÝ, J., SULEK, J. \& LORENZI, A. 2007. The cyanobacterial genus Brasilonema - molecular and phenotype evaluation. J. Phycol. 43:789-798. http://dx.doi.org/10.1111/j.1529-8817.2007.00376.x

HONDA, R.Y. \& AZEVEDO, M.T.P. 2004. Estudos taxonômicos em culturas de Cyanobacteria provenientes de um reservatório oligotrófico no Parque Estadual das Fontes do Ipiranga (PEFI), São Paulo, SP, Brasil. Hoehnea 31(2):151-169.

HOFFMANN, L., KOMÁREK, J. \& KAŠTOVSKY, J. 2005. System of cyanoprokaryotes (cyanobacteria) - state in 2004. Algol. Stud. 117:95-115. http://dx.doi.org/10.1127/1864-1318/2005/0117-0095
HOWARTH, R.W., MARINO, R. \& COLE, J.J. 1988. Nitrogen Fixation in Freshwater, Estuarine, and Marine Ecosystems. 2. Biogeochemical. Limnol. Oceanogr. 33:688-701. http://dx.doi.org/10.4319/lo.1988.33.4_ part_2.0688

KOMÁREK, J. 1985. Do all cyanophytes have a cosmopolitan distribution? Survey of the freshwater cyanophyte flora of Cuba. Algol. Stud. 71:359-386.

KOMÁREK, J. 1994. Current trends and species delimitation in the cyanoprokaryote taxonomy. Algol. Stud. 75:11-29.

KOMÁREK, J. 2003. Two Camptylonemopsis species (cyanoprokaryotes) from "Mata Atlantica" in coastal Brazil. Preslia 75:223-232.

KOMÁREK, J. 2006. Cyanobacterial taxonomy: current problems and prospects for the integration of traditional and molecular appoaches. Algae 21(4):349-375. http://dx.doi.org/10.4490/ALGAE.2006.21.4.349

KOMÁREK, J. \& ANAGNOSTIDIS, K. 1998. Cyanoprokaryota. 1. Teil Chroococcales. In Süßwasserflora von Mitteleuropa 19/1 (H. Ettl, G. Gärtner, H. Heynig \& D. Mollenhauer, eds.). Gustav Fischer, Jena.

KOMÁREK J. \& HAUER T. 2011. CyanoDB.cz. On-line database of cyanobacterial genera. http://www.cyanodb.cz (último acesso em 12/03/2011).

KOMÁREK, J. \& KOMÁRKOVÁ-LEGNEROVÁ, J. 2007. Taxonomic evaluation of the cyanobacterial microflora from alkaline marshes of northern Belize. 1. henotypic diversity of coccoid morphotypes. Nova Hedwigia 84:65-111. http://dx.doi.org/10.1127/0029-5035/2007/00840065

LEE, R.E. 2008. Phycology. Cambridge University Press, New York, p.33-80.

LEMES-DA-SILVA, N.M., BRANCO, L.H.Z. \& NECCHI-JUNIOR, O. 2010. New aerophytic morphospecies of Cyanobacteria from tropical forest fragments in northwestern São Paulo state, Brazil. Acta Bot. Bras. 24(4):916-923. http://dx.doi.org/10.1590/S010233062010000400006

NECCHI-JUNIOR, O. \& SANT'ANNA, C.L. 1986. Taxonomic studies of some Chamaesiphonales (Cyanophyceae) from the State of São Paulo, southeastern Brazil. Rev. Bras. Bot. 9:201-206.

SANT'ANNA, C.L. 1991. Two new taxa of Anabaena and other Nostocaceae (Cyanophyceae) from the State of São Paulo, southeastern Brazil. Algol. Stud. 6:527-545.

Sant'Anna, C.L. 1995. Cyanophyceae marinhas bentônicas do Parque Estadual da Illha do Cardoso, SP, Brasil. Hoehnea 22:197-216.

SANT'ANNA, C.L. 1997. Cyanophyceae marinhas bentônicas da região de Ubatuba, SP, Brasil. Hoehnea 24(2):57-74.

SANT'ANNA, C.L., AZEVEDO, M.T.P., BRANCO, L.H.Z., BRAGA, M.R.A., CORDEIRO-MARINHO, M. \& GUIMARÃES, S.M.P.B. 1995. Cianofíceas marinhas bentônicas das praias de Peruíbe e dos Sonhos, Município de Itanhaém, SP, Brasil, III. Rev. Bras. Biol. 55(3):389-407.

SANT'ANNA, C.L., AZEVEDO, M.T.P., BRANCO, L.H.Z. \& KOMÁREK, J. 2007. New aerophytic morphospecies of Nostoc (Cyanobacteria) from São Paulo State, Brazil. Hoehnea 34(1):95-101.

SANT'ANNA, C.L., AZEVEDO, M.T.P., FIORE, M.F., LORENZI, A.S., KAŠTOVSKÝ, J. \& KOMÁREK, J. 2011a. Subgeneric diversity of Brasilonema (Cyanobacteria, Scytonemataceae). Rev. Bras. Bot. 34(1):51-62

SANT'ANNA, C.L., AZEVEDO, M.T.P., KAŠTOVSKY, J. \& KOMÁREK, J. 2010. Two form-genera of aerophytic heterocytous cyanobacteria from Brasilian rain forest "Mata Atlântica". Fottea 10(2):217-228.

SANT'ANNA, C.L., BRANCO, L.H.Z. \& AZEVEDO, M.T.P. 2006. Cyanophyceae/Cyanobacteria. In Gêneros de algas de águas continentais do Brasil: chave para identificações e descrições (C.E.M. Bicudo \& M. Menezes, orgs.). 2nd ed. RIMA, São Carlos, p.19-63.

SANT'ANNA, C.L., GAMA-JUNIOR W.A., AZEVEDO, M.T.P. \& KOMÁREK, J. 2011b. New morphospecies of Chamaesiphon (Cyanobacteria) from Atlantic rainforest, Brazil. Fottea 11(1):1-6.

SANT'ANNA, C.L., XAVIER, M.B. \& SORMUS, L. 1988. Estudo qualitativo do fitoplâncton da Represa de Serraria, Estado de São Paulo, Brasil. Rev. Bras. Biol. 48(1):83-102. 
SANT'ANNA, C.L. \& SILVA, S.M.F. 1988. Capsosira brasiliensis (Cyanophyceae) from southeastern Brazil. Hoehnea 9:1-6.

SANT'ANNA, C.L., SILVA, S.M.F. \& BRANCO, L.H.Z. 1991. Cyanophyceae da Gruta-que-chora, município de Ubatuba, Estado de São Paulo, Brasil. Hoehnea 18(2):75-97.

SECKBACH, J., ed. 2007. Algae and Cyanobacteria in Extreme Environments. Springer, Netherlands.

SILVA, S.M.F. 1987. Stigonemataceae (Cyanophyceae) no estado de São Paulo, Brasil. Dissertação de Mestrado Universidade Estadual de São Paulo, Rio Claro.
SILVA, D. 2009. Revisão do gênero Planktothrix Anagnostidis \& Komárek (Cyanobacteria/Oscillatoriales) no Brasil. Tese de Doutorado, Instituto de Botânica, São Paulo.

SILVA, S.M.F. \& SANT’ANNA, C.L. 1988. Stigonema gracile sp. nov., a new taxon of Stigonemataceae (Cyanophyceae) from Brazil. Rev. Bras. Bio. 48(2):391-395.

WERNER, V.R. 2010. Cyanophyceae. In Lista de Espécies da Flora do Brasil (Jardim Botânico do Rio de Janeiro). http://floradobrasil.jbrj.gov.br/2010/ FB098990 (último acesso em 12/03/2011).

Recebido em 05/03/2011

Versão Reformulada em 22/04/201

Publicado em 09/05/2011 